\title{
Cereblon Regulates the Proteotoxicity of Tau by Tuning the Chaperone Activity of DNAJA1
}

\author{
(D) Uroos Akber, ${ }^{1,3}$ Heeji Jo, ${ }^{1,3}$ Seungje Jeon, ${ }^{1,3}$ Seung-Joo Yang, ${ }^{1,3}$ Sunhwa Bong, ${ }^{2}$ Sungsu Lim, ${ }^{4}$ Yun Kyung Kim, ${ }^{4}$ \\ Zee-Yong Park, ${ }^{2}$ and ${ }^{\circledR}$ Chul-Seung Park ${ }^{1,3}$ \\ ${ }^{1}$ Laboratory of Molecular Neurobiology, Gwangju Institute of Science and Technology (GIST), Gwangju 61005, Republic of Korea, ${ }^{2}$ Laboratory of \\ Functional and Medicinal Proteomics, School of Life Sciences, Gwangju Institute of Science and Technology (GIST), Gwangju 61005, Republic of \\ Korea, ${ }^{3}$ Integrated Institute of Biomedical Research, Gwangju Institute of Science and Technology (GIST), Gwangju 61005, Republic of Korea, and \\ ${ }^{4}$ Center for Neuromedicine, Brain Science Institute, Korea Institute of Science and Technology (KIST), Seoul 136-791, Republic of Korea
}

Protein aggregation can induce explicit neurotoxic events that trigger a number of presently untreatable neurodegenerative disorders. Chaperones, on the other hand, play a neuroprotective role because of their ability to unfold and refold abnormal proteins. The progressive nature of neurotoxic events makes it important to discover endogenous factors that affect pathologic and molecular phenotypes of neurodegeneration in animal models. Here, we identified microtubule-associated protein tau, and chaperones Hsp70 (heat shock protein 70) and DNAJA1 (DJ2) as endogenous substrates of cereblon (CRBN), a substrate-recruiting subunit of cullin4-RING-E3-ligase. This recruitment results in ubiquitin-mediated degradation of tau, Hsp70, and DJ2. Knocking out CRBN enhances the chaperone activity of DJ2, resulting in decreased phosphorylation and aggregation of tau, improved association of tau with microtubules, and reduced accumulation of pathologic tau across brain. Functionally abundant DJ2 could prevent tau aggregation induced by various factors like okadaic acid and heparin. Depletion of CRBN also decreases the activity of tau-kinases including GSK3 $\alpha / \beta$, ERK, and p38. Intriguingly, we found a high expression of CRBN and low levels of DJ2 in neuronal tissues of 5XFAD and APP knock-in male mouse models of Alzheimer's disease. This implies that CRBN-mediated DJ2/Hsp70 pathway may be compromised in neurodegeneration. Being one of the primary pathogenic events, elevated CRBN can be a contributing factor for tauopathies. Our data provide a functional link between CRBN and DJ2/Hsp70 chaperone machinery in abolishing the cytotoxicity of aggregation-prone tau and suggest that $\mathrm{Crbn}^{-1-}$ mice serve as an animal model of resistance against tauopathies for further exploration of the molecular mechanisms of neurodegeneration.

Key words: cereblon; chaperone; DNAJA1; neurodegeneration; tau phosphorylation; ubiquitin

Significance Statement

This work highlights a potential molecular mechanism by which CRBN influences the aggregation and toxicity of tau via molecular chaperone modulation. Combining in vivo techniques and molecular analyses, we show that CRBN tunes fate of tau by regulating the chaperone activity of Hsp70/DJ2 and the kinase activity of tau kinases. Knocking out CRBN relieves DJ2 to detoxify cell-damaging conformers of tau in vitro and in vivo. Consequently, tau enters into a dynamic folding pathway and associates with microtubules, rendering them intact and functional. These findings provide the rationale for proposing CRBN to influence tauopathies via tuning chaperone activities and emphasize that DJ2 can be a promising target for the treatment of tauopathies to reduce the toxicity of abnormal aggregates.

Received Sep. 23, 2020; revised Mar. 24, 2021; accepted Apr. 23, 2021

Author contributions: U.A. and C.-S.P. designed research; U.A., H.J., S.J., S.-J.Y., and S.B. performed research; S.L., Y.K.K., and Z.-Y.P. contributed unpublished reagents/analytic tools; U.A. analyzed data; U.A. wrote the paper.

This work was supported by a Gwangju Institute of Science and Technology (GIST) Research Institute grant, funded by the GIST, South Korea; and the Mid-career Research Grant (NRF2019R1A2C2087565) and the Original Technology Research Program for Brain Science (Grant NRF-2018M3C7A1056293) of the National Research Foundation of Korea, funded by the Korean government, Ministry of Science and ICT.

The authors declare no competing financial interests.

Correspondence should be addressed to Chul-Seung Park at cspark@gist.ac.kr.

https://doi.org/10.1523/JNEUROSCI.2494-20.2021

Copyright $(2021$ the authors

\section{Introduction}

Misfolded and aggregated proteins, including $\beta$-amyloid and the microtubule-associated protein tau, are hallmarks of multiple neurodegenerative diseases. Physiologic phosphorylation regulates the role of tau in governing the dynamics of microtubules during neuronal growth and development. However, aging and persistent stress may increase pathologic tau phosphorylation, leading to insoluble tau aggregation and neurodegeneration (Joseph et al., 2009). On the other hand, the upregulation of molecular chaperones has neuroprotective effects, as shown by 
several studies (Lindberg et al., 2015; Balchin et al., 2016). In particular, heat shock proteins (Hsps) are a part of the protein quality control machinery that is tasked with countering protein misfolding, proteotoxicity, and aggregation, thus maintaining proteostasis and the functionality of the proteome (Mogk et al., 2018). The typical mammalian protein refolding machinery consists of members of the DNAJ [HSP $40 \mathrm{kDa}$ (Hsp40)] family, termed "holdases," which recognize and bind to misfolded proteins, whereas members of the Hsp70 family are the core "foldases" that refold proteins to their functionally active form (Nillegoda et al., 2015). The DNAJ family is involved in diverse cellular activities including protein folding/unfolding/refolding, translation, and translocation (Qiu et al., 2006). Hsp70 serves as a potent antiaggregation chaperone, as the overexpression of Hsp70 in mice suppresses the pathologic and functional phenotypes of Alzheimer's disease (AD; Hoshino et al., 2011). DNAJA1 (DJ2) is known to recruit DnaK and numerous Hsp70s and Hsp110s, which pull on and unfold misfolded proteins within stable aggregates (De Los Rios and Goloubinoff, 2016). However, it has remained unclear whether DJ2 could prevent misfolding or aggregation as well, in addition to its ability to perceive unfolded proteins. Also, it is often unclear why these chaperones might fail in neurodegenerative diseases involving protein aggregation.

Cereblon $(\mathrm{CRBN})$ is the substrate receptor of the CUL4A/BRoc1-RBX1 E3-ubiquitin ligase $\left(\mathrm{CRL} 4^{\mathrm{CRBN}}\right)$ that triggers the recruitment and proteasomal degradation of endogenous and thalidomide-targeted substrates. CRBN mediates the ubiquitylation (Ubn) of the chloride channel protein 1 (Chen et al., 2015), large-conductance calcium-activated potassium $\left(\mathrm{BK}_{\mathrm{Ca}}\right)$ channel (Choi et al., 2018), and presynaptic proteins (Del Prete et al., 2016), and, thus, can regulate learning and memory (Bavley et al., 2018; Song et al., 2018). c-Jun also undergoes CRBN-mediated Ubn and degradation so that the activity of c-Jun-associated transcription factors is repressed. We reported the role of CRBN in regulating the protein levels of glutamine synthetase (Nguyen et al., 2016) in elevated AMPK activity (Lee et al., 2011; Yang et al., 2020) and in epigenetic regulation of Kcna3-encoding Kv1.3 potassium channel, which affects the activation of $\mathrm{CD} 4{ }^{+} \mathrm{T}$ cell (Kang et al., 2016). Also, we reported the role of CRBN in synaptic function and animal behavior (Choi et al., 2018). In addtion, CRBN promotes immunomodulatory imide drug (IMiD)-induced degradation of several cellular proteins (e.g., two transcription factors IKZF1 and IKZF3), resulting in the death of multiple myeloma cells (Sievers et al., 2018). As yet, only a few targets of CRBN have been identified, although $\sim 224$ binding proteins for CRBN have been reported as showing altered abundances in the presence of IMiDs (Zhu et al., 2014). Binding of IMiDs to CRBN prevents the Ubn of CRBN with consequently increased degradation of binding proteins (Liu et al., 2015). Because CRBN is critical in recruiting assorted substrates, it can regulate a plethora of pathological and physiological conditions.

Our previous study elaborating the ability of the $\mathrm{Crbn}^{-1-}$ cell line to resist various stressors opened a new direction of research to validate the possible mechanisms underlying stress resistance (Lee et al., 2015). In the present study, we considered molecular chaperones as the possible candidates governing this unusual competence, as they are highly efficient in selectively spotting misfolded proteins and maintaining them in a soluble state. Here we show how the chaperones Hsp70 and DJ2 can be tuned to treat tauopathies and render the $\mathrm{Crbn}^{-1-}$ cells and mice resistant to various stressors.
Table 1. Antibodies used in the study

\begin{tabular}{|c|c|c|}
\hline Antibodies & Source & Catalog number \\
\hline$\alpha$-CRBN & Sigma-Aldrich & HPA045910, RRID:AB_10960409 \\
\hline$\alpha$-CRBN & Abnova & H00051185-B01P; RRID:AB_1573181 \\
\hline$\alpha$-DJ2 & Abcam & ab3089 (discontinued product) \\
\hline$\alpha$-DJ2 & Abcam & ab126774; RRID:AB_11127505 \\
\hline$\alpha$-FLAG & CST & 2368S; RRID:AB_2217020 \\
\hline$\alpha$-FLAG & Sigma-Aldrich & F1804; RRID:AB_262044 \\
\hline$\alpha$-HA & Santa Cruz Biotechnology & sc-7392; RRID:AB_627809 \\
\hline$\alpha-\mathrm{HA}$ & Abcam & ab9110; RRID:AB_307019 \\
\hline$\alpha$-ACTIN & Sigma-Aldrich & A0483; RRID:AB_1840146 \\
\hline$\alpha-p 38$ & Abcam & ab27986; RRID:AB_881844 \\
\hline$\alpha-\mathrm{p}-\mathrm{p} 38$ & CST & 9216; RRID:AB_331296 \\
\hline$\alpha-\mathrm{GAPDH}$ & AbFrontier & PA0018; RRID:AB_1616734 \\
\hline$\alpha$-Tubulin & Sigma-Aldrich & T6199; RRID:AB_477583 \\
\hline$\alpha$-Мyс & Millipore & 05-419; RRID:AB_309725 \\
\hline$\alpha$-AMPK $\alpha$ & CST & 2532S; RRID:AB_330331 \\
\hline$\alpha$-рАМРК $\alpha$ & CST & 2535S; RRID:AB_331250 \\
\hline$\alpha$-pSer202/Thr205 & Thermo Fisher Scientific & MN1020; RRID:AB_223647 \\
\hline$\alpha-\mathrm{pS} 199$ & Innovative Research & 44734G; RRID: AB_1502104 \\
\hline$\alpha-p S 231$ & Innovative Research & 44746G; RRID:AB_1502124 \\
\hline$\alpha-\mathrm{pS} 356$ & Thermo Fisher Scientific & 44-751G; RRID:AB_2533744 \\
\hline$\alpha$-pS396 & Thermo Fisher Scientific & 44752G, RRID:AB_2533745 \\
\hline$\alpha$-рT181 & Thermo Fisher Scientific & 701530; RRID:AB_2532491 \\
\hline$\alpha$ - pSer400/Thr403/Ser404 & CST & 11837; discontinued product \\
\hline$\alpha$-TAU & Innovative Research & AHB0042; RRID:AB_1502093 \\
\hline$\alpha$-TAU & Abcam & Ab32057; RRID:AB_778254 \\
\hline$\alpha$-pGSK-3 $\alpha / \beta$ & CST & 9331; RRID:AB_329830 \\
\hline$\alpha$-GSK-3 $\alpha / \beta$ & BD Biosciences & 610202; RRID:AB_397601 \\
\hline$\alpha-\mathrm{pERK} 1 / 2$ & CST & 9101; RRID:AB_2572926 \\
\hline$\alpha$-ERK1/2 & BD Transduction & 610408; RRID:AB_397790 \\
\hline$\alpha-\mathrm{MOAB}-2$ & Novus Biologicals & NBP2-13075 \\
\hline$\alpha-\mathrm{HSP70}$ & CST & 4872; RRID:AB_2279841 \\
\hline$\alpha-H S P 70$ & Santa Cruz Biotechnology & sc-32239; RRID:AB_627759 \\
\hline$\alpha-\mathrm{HSP70}$ & Abcam & $\begin{array}{l}\text { ab181606 (RRID number not } \\
\text { available) }\end{array}$ \\
\hline$\alpha-\mathrm{HSP70}$ & Abcam & AF1663; RRID:AB_2233171 \\
\hline $\begin{array}{l}\text { Alexa Fluor-488 } \\
\text { anti-mouse }\end{array}$ & Thermo Fisher Scientific & A11029; RRID:AB_138404 \\
\hline $\begin{array}{l}\text { Alexa Fluor-488 } \\
\text { anti-rabbit }\end{array}$ & Thermo Fisher Scientific & A11034; RRID:AB_2576217 \\
\hline $\begin{array}{l}\text { Alexa Fluor-594 } \\
\text { anti-mouse }\end{array}$ & Thermo Fisher Scientific & A11005; RRID:AB_141372 \\
\hline Texas Red anti-rabbit & Thermo Fisher Scientific & T6391; RRID:AB_10374713 \\
\hline
\end{tabular}

\section{Materials and Methods}

Experimental animals and cell lines. The generation and screening of CRBN-knock-out (KO) mice have been described previously (Lee et al., 2013). Wild-type (WT) and CRBN-KO male mice were maintained on a standard chow diet and water ad libitum in pathogen-free conditions with a $12 \mathrm{~h}$ light/dark cycle. APP knock-in and 5XFAD male mice expressing five mutations in human $\mathrm{A} \beta \mathrm{PP}$ and PS1 (B6SJL-Tg $\left[\mathrm{A} \beta \mathrm{PP}{ }^{\star} \mathrm{K} 670 \mathrm{~N}^{\star} \mathrm{M} 671 \mathrm{~L}^{\star}\right.$ I716V*V717I, PSEN1 ${ }^{\star}$ M146*L286V] 6799Vas/J) under the Thyl promoter were purchased from The Jackson Laboratory. All experiments and paradigms were approved by the Gwangju Institute of Science and Technology Animal Care and Use Committee. Effort was made to minimize the number of animals used and their suffering. Human neuroblastoma cell line SHSY5Y (Thermo Fisher Scientific), human embryo kidney (HEK) cells, and mouse embryo fibroblasts (MEFs) were maintained in DMEM (Thermo Fisher Scientific) supplemented with 10\% fetal bovine serum (FBS; Thermo Fisher Scientific) and $100 \mathrm{U} / \mathrm{ml}$ antibiotic-antimycotic (Thermo Fisher Scientific) at $37^{\circ} \mathrm{C}$ with $5 \% \mathrm{CO}_{2}$. CRISPR/cas9 system was used to knock out $C R B N$ from the cells and was confirmed through Western blot. Antibodies and reagents are listed in Tables 1 and 2. Primers and vectors used in this study are shown in Extended Data Table 2-1. 
Table 2. Reagents and peptides used in the study

\begin{tabular}{|c|c|c|}
\hline Reagent & Source & Catalog number \\
\hline Thalidomide & Sigma-Aldrich & $50-35-1$ \\
\hline Cycloheximide & Sigma-Aldrich & $66-81-9$ \\
\hline Okadaic Acid & CST & 5934 \\
\hline IPTG & Sigma-Aldrich & $367-93-1$ \\
\hline ThT & Sigma-Aldrich & $9041-08-1$ \\
\hline Lipofectamine 2000 & Thermo Fisher Scientific & 11668019 \\
\hline Tubulin tracker-green & Thermo Fisher Scientific & T34075 \\
\hline PMSF & Sigma-Aldrich & 10837091001 \\
\hline Protease inhibitor cocktail & Calbiochem & 535140 \\
\hline Normal goat serum & Abcam & Ab7481 \\
\hline Aquamount & Thermo Fisher Scientific & TA-125-AM \\
\hline Hoescht Dye & Abcam & 145597 \\
\hline FSC22 clear & Leica & 3801480 \\
\hline DAB substrate & Vector Laboratories & SK-4100 \\
\hline TRIzol reagent & Zymo Research & R2050-1-50 \\
\hline Immobiline DryStrip pH 3-10 & GE Healthcare & $17-6001-11$ \\
\hline ProteinG Sepharose & GE Healthcare & $17-0618-01$ \\
\hline Glutathione agarose & Thermo Fisher Scientific & 16100 \\
\hline Metal Affinity resin & Clontech & 635502 \\
\hline Flag M2 agarose beads & Sigma-Aldrich & A2220 \\
\hline Ubiquitin & Boston Biochem & $\mathrm{U}-100 \mathrm{H}$ \\
\hline UBE1 & Boston Biochem & $\mathrm{E}-305$ \\
\hline UBE2D1 & Boston Biochem & $\mathrm{E} 2-616$ \\
\hline Me-Ub & Boston Biochem & U-501 \\
\hline Recombinant protein Tau40 & This study & NA \\
\hline Recombinant protein Tau-K18 & This study & NA \\
\hline Recombinant protein DNAJA1 & This study & NA \\
\hline Recombinant protein DNAJB1 & This study & NA \\
\hline Recombinant protein Hsp70 & This study & NA \\
\hline
\end{tabular}

NA, Not available.

Immunoprecipitation. Cells were lysed in RIPA buffer $(20 \mathrm{~mm}$ HEPES, 150 mм NaCl, 1 mм EDTA-EGTA, 1\% Triton X-100, 1\% NP$40,1 \%$ sodium deoxycholate, $2 \mathrm{~mm} \mathrm{Na}_{4} \mathrm{VO}_{3}$, and $100 \mathrm{~mm} \mathrm{NaF}, \mathrm{pH} 7.4$, supplemented with PMSF and protease inhibitor cocktail) or Tris buffer (20 mM Tris, pH 7.4, and $0.32 \mathrm{~m}$ sucrose, supplemented with PMSF and protease inhibitor cocktail) followed by centrifugation at $12,500 \mathrm{rpm}$ for $30 \mathrm{~min}$. Proteins were immunoprecipitated with the specified antibodies for $16 \mathrm{~h}$ at $4^{\circ} \mathrm{C}$, followed by incubation with protein G Sepharose 4 Fast Flow for $2.5 \mathrm{~h}$ at $4^{\circ} \mathrm{C}$. Afterward, the beads were washed twice in RIPA or Tris buffer and twice in PBS. Immunoprecipitated proteins were resolved by SDS-PAGE, transferred to a PVDF membrane, and analyzed by immunoblotting with the specified antibodies.

Transfection. A total of $1 \times 10^{5}$ cells was seeded in six-well plates and transfected with 500-1000 ng of DNA the next day using Lipofectamine 2000. Negative control samples were transfected with Empty Vector (EV). Cells were harvested after $16 \mathrm{~h}$ for lysis or next step.

Immunohistochemistry. The animals were killed, brain samples were fixed in $4 \%$ paraformaldehyde at $4^{\circ} \mathrm{C}$ for $48 \mathrm{~h}$, embedded in a frozen section compound (OCT), and sectioned at $5 \mu \mathrm{m}$ thickness. For antigen retrieval, the sections were placed in a citrate buffer, $\mathrm{pH}$ 6.0, and heated in an incubator at $90^{\circ} \mathrm{C}$ for $45 \mathrm{~min}$. Endogenous peroxidase activity was blocked by placing the sections in $0.3 \% \mathrm{H}_{2} \mathrm{O}_{2}$ in methanol for $15 \mathrm{~min}$ at room temperature. Blocking was conducted for $1 \mathrm{~h}$ at $4^{\circ} \mathrm{C}$ in blocking buffer (1\% BSA, $10 \%$ goat serum in TBST, and $0.3 \mathrm{~m}$ glycine). Sections were then incubated overnight at $4^{\circ} \mathrm{C}$ with primary antibodies $(1: 1000)$, washed, and incubated with the corresponding Alexa Fluor-conjugated secondary antibodies. Fluoview Viewer (Olympus) was used to image and quantify the fluorescence in each brain section. As a control, the primary antibody was omitted from several test sections in each experiment. The sections were counterstained with Hoechst dye before mounting.

MG132 and cycloheximide chase and experiments. Cells were seeded overnight in complete medium in six-well plates $\left(1 \times 10^{4}\right.$ cells/well $)$, and then $2.5 \mu \mathrm{g} / \mathrm{ml}$ cycloheximide (CHX) or $0.5 \mu \mathrm{g} / \mathrm{ml} \mathrm{MG132}$ was added.
Following the addition of reagent, samples were harvested at the indicated time points for immunoblot analysis.

Stereotaxic injections of okadaic acid into mouse brains. Stereotaxic surgery was conducted as follows. Mice were anesthetized with $6 \times$ ketamine $(0.1 \mathrm{ml} / 10 \mathrm{~g}$ body weight), depilated, given local anesthesia (lidocaine, $0.3 \mathrm{ml}$ ), and placed securely in the ear bars. Mice were injected unilaterally in the lateral amygdala (bregma coordinates: anteroposterior, -1.94 ; mediolateral, -3.15 ; dorsoventral, -4.5 ) with $130 \mathrm{nl}$ of 100 $\mu \mathrm{M}$ okadaic acid (OA; Sigma-Aldrich) dissolved in DMSO or DMSO alone, at an infusion rate of $60 \mathrm{nl} / \mathrm{min}$ (Baker and Götz, 2016). After the injection, the needle was left inserted for $5 \mathrm{~min}$, then slowly withdrawn, and the scalp was securely stitched. Postoperative analgesia and antibiotic were administered intramuscularly once reflexes returned (septazol, $0.05 \mathrm{ml}$; ketapro, $0.05 \mathrm{ml}$ ), and mice were returned to their home cages. Mice were left to recover for $24 \mathrm{~h}$. Brains were removed from the skull, perfused with PBS, dissected to obtain the regions shown in Figure $8 C$, and snap frozen in liquid nitrogen.

Bimolecular fluorescence complementation assay. $C R B N^{+/+}$and $C R B N^{-1-}$ SH-SY5Y cells were seeded on coverslips in complete medium in six-well plates $\left(1 \times 10^{4}\right.$ cells/well). Cells were cotransfected with tau40-VN173 and tau40-VC155 constructs. After $16 \mathrm{~h}$, cells were treated with $30 \mathrm{~nm}$ OA for $24 \mathrm{~h}$. The cellular intensities of tau-bimolecular fluorescence complementation (BiFC) fluorescence were analyzed using an FV1000 Confocal Laser-Scanning Microscope (Olympus).

Analysis of tau disassembly from microtubules. $\mathrm{CRBN}^{+/+}$and $C R B N^{-1-}$ SH-SY5Y cells were seeded on coverslips in complete medium in six-well plates $\left(1 \times 10^{4}\right.$ cells/well $)$ and treated with $30 \mathrm{~nm}$ OA overnight. Cells were extracted in MTSB (microtubule-stabilizing buffer; 80 mm PIPES, pH 6.8, 1 mm EGTA, $\left.1 \mathrm{~mm} \mathrm{MgCl}_{2}\right)$ and $1.5 \%$ TBST $(0.1 \%$ Triton X-100 in TBS), for $30 \mathrm{~s}$, fixed in methanol at $20^{\circ} \mathrm{C}$ for $2 \mathrm{~min}$, and rinsed well with TBST. Then cells were blocked with $1 \%$ BSA/TBST for $1 \mathrm{~h}$, rinsed with TBST, and incubated with anti-tau antibody and tubulin tracker in the dark for $1 \mathrm{~h}$ at room temperature. Alexa Fluor-594 secondary antibody was added after washing with TBST and incubated in the dark for $1 \mathrm{~h}$ at room temperature. The cells were then imaged with an FV1000 Confocal Laser-Scanning Microscope (Olympus) equipped with a $100 \times$, numerical aperture 1.40 , oil-immersion objective.

Tau40 and K18 aggregation assay. The aggregation of K18 tau, fulllength Tau40 protein, and Alzheimer-like PHF of tau ( $5 \mu \mathrm{M}$ each) was performed at $37^{\circ} \mathrm{C}$ in the presence of polyanions [heparin, $2.5 \mu \mathrm{M}$ for K18; and Tau40, $6 \mu \mathrm{M}$ for Alzheimer-like PHF (paired helical filaments) of tau] in PBS, for $4 \mathrm{~h}, 96 \mathrm{~h}$, and $9 \mathrm{~d}$, respectively. The $200 \mu \mathrm{l}$ reaction mixtures, containing $12 \mu \mathrm{M}$ tau, $10 \mathrm{~mm} \mathrm{Na}_{2} \mathrm{PO}_{4}, \mathrm{pH} 7.4,50 \mathrm{~mm}$ ammonium acetate, $1 \mathrm{~mm}$ dithiothreitol (DTT), and $6 \mu \mathrm{m}$ heparin, were incubated at $37^{\circ} \mathrm{C}$ for $9 \mathrm{~d}$ to promote Alzheimer-like PHF formation. Assembly was followed quantitatively by fluorescence assay using Thioflavin $\mathrm{T}$ (ThT). Dithiothreitol was added at a final concentration of $1 \mathrm{~mm}$ to avoid intramolecular disulfide cross-linking. For each state (preaggregates, aggregates, aggregates with DJ2), samples were transferred to a black 98-well plate with PBS containing $5 \mu \mathrm{M}$ ThT (Sigma-Aldrich). The ThT signal was measured at $\lambda_{\mathrm{ex}}=430 \mathrm{~nm}$ and $\lambda_{\mathrm{em}}=480 \mathrm{~nm}$ in a Synergy H1 Hybrid Reader (BioTek).

Identification of CRBN binding partners by liquid chromatographytandem mass spectrometry. Whole-brain tissues powdered in liquid nitrogen were resuspended in lysis buffer $(8 \mathrm{M}$ urea, $75 \mathrm{~mm} \mathrm{NaCl}, 50 \mathrm{~mm}$ Tris, $\mathrm{pH} 8.2$, protease inhibitor cocktail, $1 \mathrm{~mm} \mathrm{NaF}, 1 \mathrm{~mm} \beta$-glycerophosphate, $1 \mathrm{~mm}$ sodium orthovanadate, $10 \mathrm{~mm}$ sodium pyrophosphate, $1 \mathrm{~mm}$ PMSF) by sonication. Proteins were then reduced in a final concentration of $5 \mathrm{~mm} \mathrm{DTT}$ for $30 \mathrm{~min}$ at $37^{\circ} \mathrm{C}$ and alkylated using a final concentration of $25 \mathrm{~mm}$ isoamyl alcohol during $30 \mathrm{~min}$ at room temperature in the dark. After alkylation, urea concentration was diluted to $<2 \mathrm{M}$ using $25 \mathrm{~mm}$ Tris- $\mathrm{HCl}, \mathrm{pH} 8.0$, and digested overnight at $37^{\circ} \mathrm{C}$ with trypsin at 1:50 dilution.

Digested proteins were subjected to multidimensional protein identification technology (MudPIT) analysis with modifications to the method described previously (Yates et al., 1999). MudPIT columns were constructed with an analytical column-a $100 \mu \mathrm{m}$ inner diameter (i.d.) fused silica capillary column (Polymicro Technologies) containing $7 \mathrm{~cm}$ of $5 \mu \mathrm{m}$ Aqua C18 material (Phenomenex) - and a trapping column - a 
$250 \mu \mathrm{m}$ i.d. fused silica capillary column packed with $2 \mathrm{~cm}$ of a $5 \mu \mathrm{m}$ Partisphere strong cation exchanger (Whatman) and $2 \mathrm{~cm}$ of $5 \mu \mathrm{m}$ Aqua C18 reversed-phase column material (Phenomenex). After peptide elution from the microcapillary column, the peptides were electrosprayed into an LTQ Linear Ion Trap Mass Spectrometer (Thermo Fisher Scientific), with a $2.3 \mathrm{kV}$ spray voltage used distally and applied to the waste of the HPLC split. A cycle of a full-scan mass spectrum (400-1400 mass-to-charge ratio) followed by nine data-dependent MS/MS spectra at $35 \%$ normalized collision energy was repeated continuously throughout the multidimensional separation. The MS/MS spectra obtained from the coupled-column LC- electrospray ionization-MS/MS analyses were used to search the mouse International Protein Index database version 3.78 using BioWorks version 3.2. SEQUEST was searched with a fragment ion mass tolerance of $1.0 \mathrm{Da}$ and a parent ion tolerance of 3.0 Da. The iodoacetamide derivative of cysteine was allowed in SEQUEST as a fixed modification (cysteines, +57). Oxidation of methionine and acetylation of lysine were assigned in SEQUEST searches as a variable modification (methionine, +16 ) with a maximum of three modifications allowed per peptide (the maximum number of modification per type was five), and a maximum of two missed cleavage sites for trypsin digestion. Proteins that contained similar peptides and could not be differentiated based on MS/MS analysis alone were grouped to satisfy the principles of parsimony. BioWorks version 3.2 was used to filter the search results, and the following Xcorr values and a $\delta \mathrm{Cn}$ value of 0.08 were applied to the following different charge states of peptides: 1.8 for singly charged peptides; 2.5 for doubly charged peptides; and 3.5 for triply charged peptides. A requirement of both of the two tryptic-digested ends was used in the filtering process.

Protein expression and purification of recombinant proteins. CRBNGST (glutathione $S$-transferase) was purified on glutathione resin (Thermo Fisher Scientific) followed by digestion with TEV (Tobacco Etch Virus) protease [isopropylthio-galactoside (IPTG), $0.5 \mathrm{~mm}$; lysis buffer: $30 \mathrm{~mm}$ Tris- $\mathrm{HCl}$ at $\mathrm{pH} 7.6,0.2 \mathrm{M} \mathrm{NaCl}, 10 \%$ glycerol; wash buffer: $30 \mathrm{~mm}$ Tris- $\mathrm{HCl}$ at $\mathrm{pH}$ 7.6, $0.2 \mathrm{M} \mathrm{NaCl}, 10 \%$ glycerol; elution buffer: 30 mм Tris- $\mathrm{HCl}$ at $\mathrm{pH} 7.6,0.2 \mathrm{~m} \mathrm{NaCl}, 10 \%$ glycerol]. TAU-6xHis, DJ16xHis, DJ2-6xHis, and Hsp70-6xHis were purified on Ni-NTA affinity resin (Clontech; IPTG, $0.1 \mathrm{~mm}$; lysis buffer: $50 \mathrm{~mm}$ HEPES-KOH, $0.5 \mathrm{M}$ $\mathrm{NaCl}$; wash buffer: $50 \mathrm{~mm}$ HEPES-KOH, $0.5 \mathrm{M} \mathrm{NaCl}, 50 \mathrm{~mm}$ imidazole; elution buffer: $50 \mathrm{~mm}$ HEPES-KOH, $0.5 \mathrm{M} \mathrm{NaCl}, 0.5 \mathrm{M}$ imidazole).

Immunoblot analysis. Cells or tissues were lysed in RIPA or Tris buffer supplemented with PMSF and protease inhibitor cocktail (Roche). Lysates were cleared by centrifugation at $12,500 \mathrm{rpm}$ for $30 \mathrm{~min}$ and quantified by the Bradford method. Equal amounts of protein $(10 \mu \mathrm{g} / \mathrm{lane})$ were separated by SDS-PAGE and transferred to a PVDF membrane. The membranes were blotted with the specified antibodies. $\alpha$-Rabbit or $\alpha$-mouse antibodies conjugated to horseradish peroxidase were used as secondary antibodies, and the signal was detected using ECL Western blotting detection reagents (GE Healthcare).

In vitro ubiquitylation assay. The ubiquitylation assay was performed as previously described (Nguyen et al., 2016). Briefly, SH-SY5Y cells cultured in six-well plates were transfected with FLAG-CRBN or $\mathrm{EV}$, and, $48 \mathrm{~h}$ later, were treated with MG132 (10 $\mu \mathrm{M})$ for $4 \mathrm{~h}$. The cells were harvested and lysed in RIPA buffer, and immunoprecipitated with Flag M2 agarose beads for $2-4 \mathrm{~h}$ at $4^{\circ} \mathrm{C}$. After washing two times with RIPA buffer and two times with Ubn buffer (50 mm Tris- $\mathrm{HCl}$, pH 8.0,

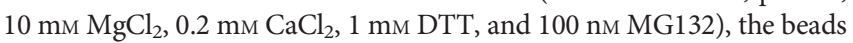
were incubated for $1 \mathrm{~h}$ at $30^{\circ} \mathrm{C}$ in $30 \mu \mathrm{l}$ of ubiquitylation buffer containing E1 $(0.5 \mu \mathrm{M}), \mathrm{UbcH} 5 \mathrm{a}(0.5 \mu \mathrm{M}), \mathrm{UbcH} 3(1.67 \mu \mathrm{M})$, ubiquitin $(60 \mu \mathrm{M})$, and ATP $(4 \mathrm{~mm})$. Methylated ubiquitin (Me-Ub) was also added where specified. Reactions were stopped by adding SDS sample buffer and subjected to immunoblot analysis.

Cell-based ubiquitylation assay. CRBN ${ }^{-1-}$ SH-SY5Y cells $\left(1 \times 10^{5}\right)$ were seeded in six-well plates and transfected with $1 \mu \mathrm{g}$ of pRK5-HAUb. FLAG-CRBN was transfected to one sample to rescue the CRBN. After $24 \mathrm{~h}$, cells were harvested, washed twice with ice-cold PBS, and lysed in Ubn buffer (50 mM Tris- $\mathrm{HCl}, 150 \mathrm{~mm} \mathrm{NaCl}, 1 \mathrm{~mm}$ EDTA, $0.5 \%$ Triton X-100) supplemented with PMSF and protease inhibitor cocktail. Lysates were incubated with $\alpha$-DJ2 or $\alpha$-Hsp70 antibody at $4^{\circ} \mathrm{C}$ overnight and immunoprecipitated with protein $\mathrm{G}$ resin. Beads were washed
Table 3. MS/MS analysis of whole-brain lysates from $\mathrm{Crbn}^{+/+}$versus $\mathrm{Crbn}^{-1-}$ mice

\begin{tabular}{lllrll}
\hline No. & Chaperones & Fold increase & No. & Redox proteins & Fold increase \\
\hline 1 & DNAJA1 & 5.0 & 1 & Peroxide reductase Prdx3 & 3.5 \\
2 & DNAJA2 & 4.0 & 2 & Dihydropteridine reductase & 3.5 \\
3 & DNAJB6 & 2.0 & 3 & Carbonyl reductase1 & 2.3 \\
4 & DNAJC5 & 2.5 & 4 & Aflatoxin reductase Akr7a5 & 3.0 \\
5 & DNAJC6 & 1.0 & 5 & Thioredoxin reductase 1 & 2 \\
6 & DNAJB1 & 3.0 & 6 & Thioredoxin reductase 2 & 2 \\
7 & Hsp90Cdc37 & 4.0 & 7 & Cytochrome P450 reductase & 1.5 \\
8 & Hsp70 & 1.5 & 8 & Aldolase reductase & 1.5 \\
9 & Hsp90aa1 & 1.8 & 9 & Flavin reductase & 1.0 \\
10 & Hspa4 & 2.0 & 10 & DHRS1 & 1.5 \\
\hline
\end{tabular}

Quantitative mass spectrometry of whole-brain lysates of $\mathrm{crbn}^{+/+} \mathrm{crbn}^{-/-}$mice was performed. Table shows the list of chaperones and redox proteins filtered from the upregulated proteins.

thoroughly with Ubn buffer and PBS. Reactions were stopped by adding SDS sample buffer, separated by SDS-PAGE, transferred to a PVDF membrane, and subjected to immunoblot analysis.

RNA purification, reverse transcription, and quantitative RT-PCR. Total RNA was extracted with TRIzol reagent according to the manufacturer protocol. cDNA was synthesized with $5 \mu \mathrm{g}$ of total RNA using MMLV Reverse Transcriptase (Thermo Fisher Scientific) according to the manufacturer instructions. Quantitative real-time PCR amplifications were conducted in an Applied Biosystems StepOne Plus machine using 96-well plates with SYBR Select Mastermix (Thermo Fisher Scientific) The relative amount of the target gene was calculated using $2^{-\Delta \Delta \mathrm{CT}}$ i.e., $2^{\text {(Ct test gene-Ct GAPDH) }}(\mathrm{Ct}$, threshold cycle).

Generation of CRBN knock-out cell lines by CRISPR/Cas9. CRBN CRISPR/Cas9 KO plasmid and the CRBN HDR plasmid (catalog \#sc412142) were purchased from Santa Cruz Biotechnology, and the manufacturer protocol was followed to knock out CRBN. Briefly, SHSY-5Y, MEFs, and HEK293T cells were cotransfected with the CRBN CRISPR/ Cas9 KO plasmid and the CRBN HDR plasmid or the control CRISPR plasmid (catalog \#sc-418922) either. Puromycin was used to select cells with successful Cas-9-induced DSBs (DNA containing double-strand breaks).

CRBN knockdown. DJ2-siRNA, CRBN-siRNA, GAPDH-siRNA, and scramble-siRNA (control) were purchased from Thermo Fisher Scientific, and cell transfection was accomplished according to the manufacturer protocol, with minor modifications. Target cells were transfected with siRNA with Lipofectamine 2000. Knock-down efficiency was analyzed by immunoblot.

Experimental design and statistical analysis. All in vivo experiments were performed on age-matched WT control, CRBN-KO, APP knockin, and 5XFAD mice. All data were generated by at least three replicates from independently performed experiments, and the total number of mice or tissues used per group is given in the figure legends. Male mice were used, and the sample size $(n)$ was determined based on the literature. All data are presented as the mean \pm SEM of $n$ independent experiments. In all figures, bars and lines show the mean and error bars show the SEM. Data were analyzed by Student's $t$ test for the comparison of two groups or one-way ANOVA for multiple groups. Excel was used for statistical analysis. $p$ Values $<0.05$ were considered statistically significant. The $p$ values were presented as ${ }^{*} p<0.05,{ }^{* *} p<0.01$, ${ }^{* * *} p<0.001$, or ns (no significant difference).

Data availability. Further information and requests for material should be directed to and will be fulfilled by C.-S.P. at cspark@gist.ac.kr.

\section{Results}

\section{Identification of Hsp70 and DJ2 as endogenous substrates of} CRBN

To identify the new substrates of CRBN, we hypothesized that the endogenous substrates of CRBN might be accumulated in $\mathrm{Crbn}^{-1-}$ animals and cell lines. We performed quantitative mass spectrometry of whole-brain lysates (WBLs) of WT $\left(\mathrm{Crbn}^{+/+}\right)$ 

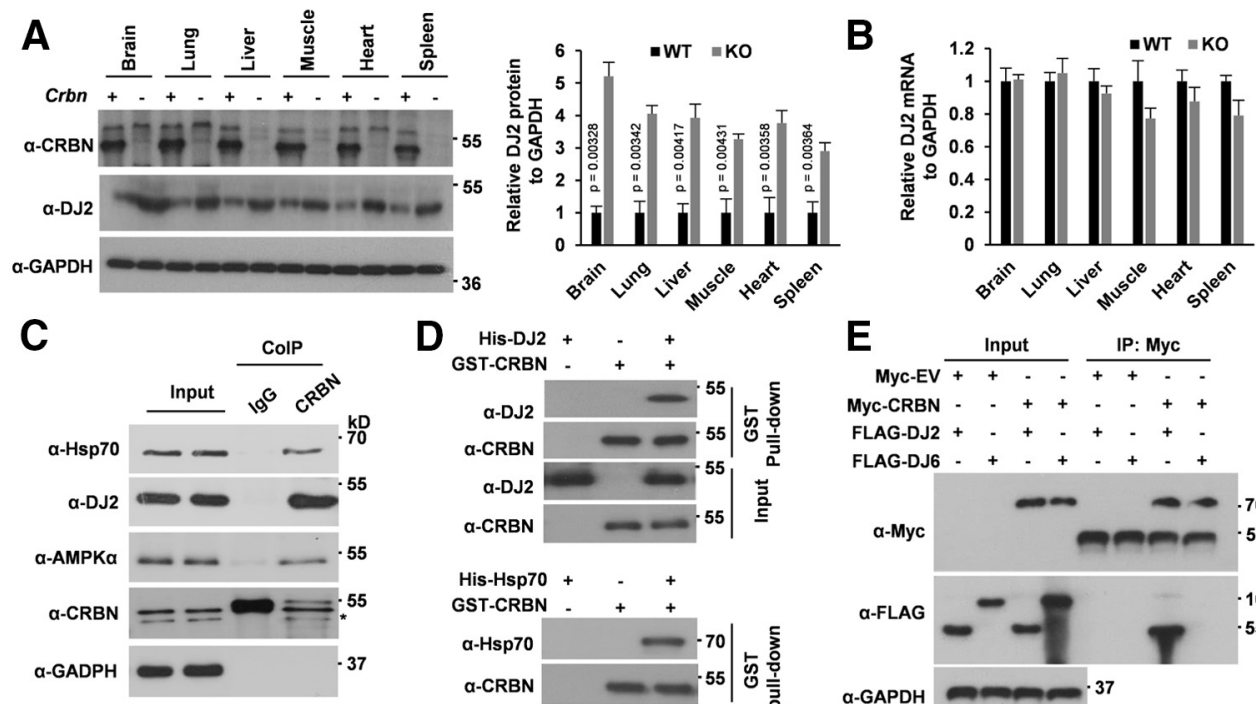

$\mathbf{E}_{\text {Myc-EV }} \frac{\text { Input }}{++\cdots} \frac{\text { IP: Myc }}{++\cdots}$

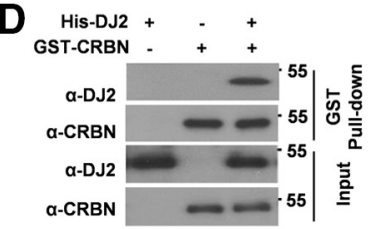

$\begin{array}{llllll}\text { Myc-CRBN - } & - & + & + & - & + \\ \text { FLAG-DJ2 + } & + & + & + & + & +\end{array}$

FLAG-DJ6 - + $++\ldots+$

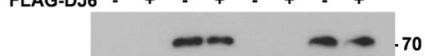

GST-CRBN - + +

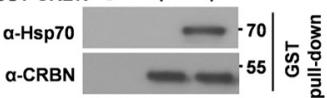

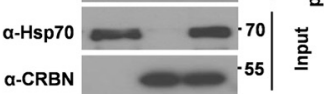
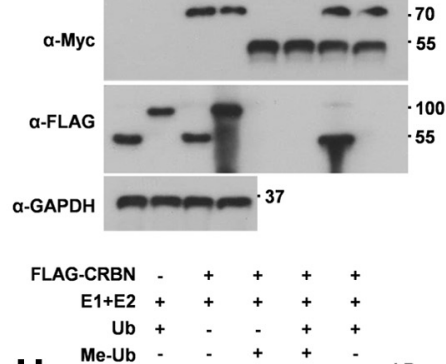

$\mathbf{F}$

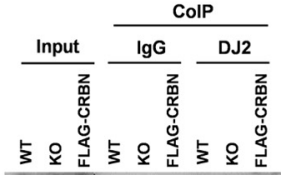

G

Input $\frac{\text { ColP }}{\operatorname{lgG} \text { Hsp70 }}$

H

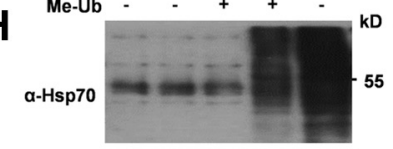

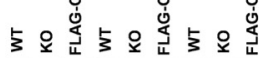

kD

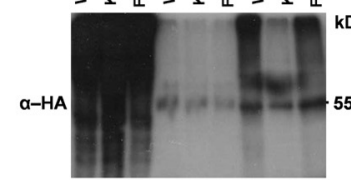

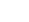
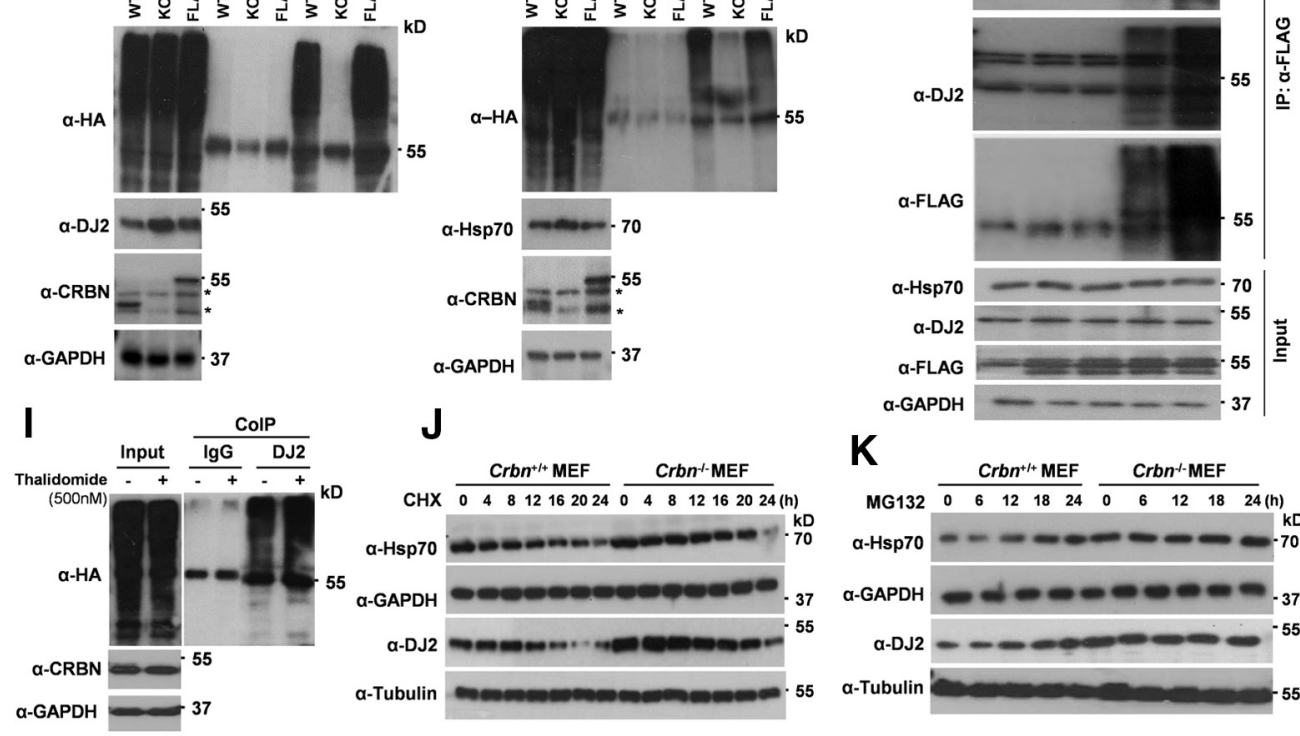

\section{J}

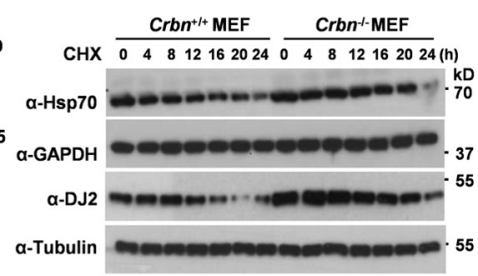

K
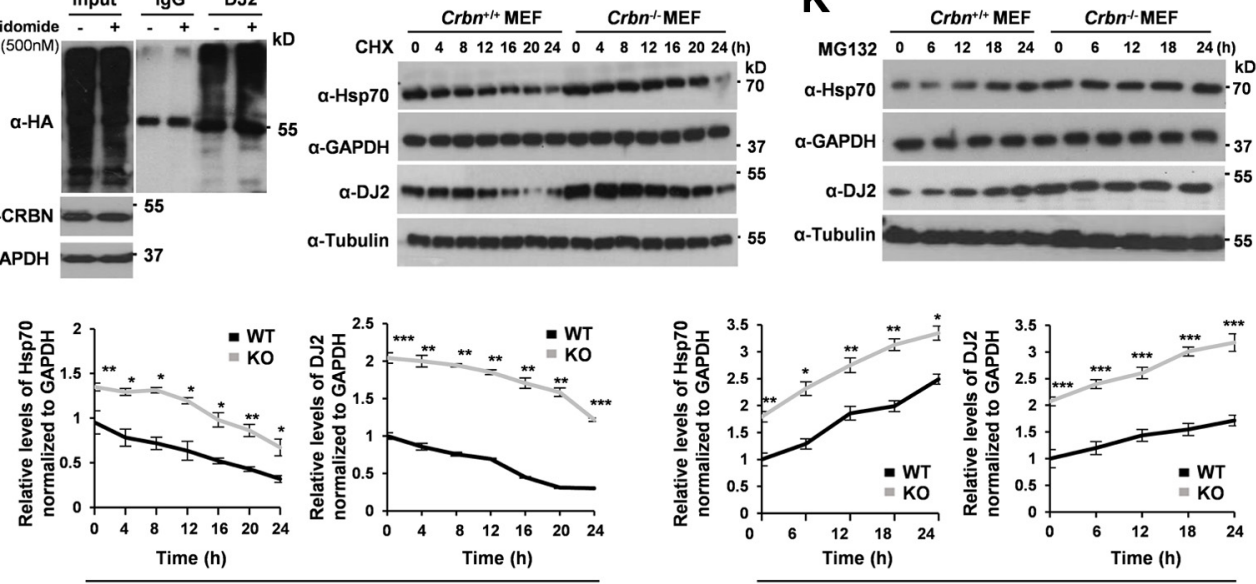

CHX chase assay

MG132 chase assay

Figure 1. Hsp70 and DJ2 are endogenous substrates of CRL4 ${ }^{\mathrm{CRBN}}$. $\boldsymbol{A}$, DJ2 levels are high in the organs of $\mathrm{Crbn}^{-1-}$ mice. Organs of five male mice from each group were homogenized in Tris buffer and immunoblotted ( $\alpha$-CRBN; Abnova). Statistical analysis is shown in the adjacent panel (Student's $t$ test). $\boldsymbol{B}$, The mRNA level of DJ2 is similar in the organs of $\mathrm{Crbn}^{-1-}$ mice. The expression of DJ2 in various tissues was analyzed by quantitative RT-PCR. The level of DJ2 mRNA expression in five male mice from each group was normalized to the GAPDH mRNA level. The relative DJ2 mRNA level is shown as a mean of triplicates of quantitative PCR in each sample, and error bars indicate \pm SD; $p>0.05$, Student's $t$ test. C, SH-SY5Ycells were lysed in Tris buffer, immunoprecipitated with rabbit IgG control or $\alpha$-CRBN antibody, and probed with the indicated antibodies ( $\alpha$-CRBN; Sigma-Aldrich). For the CRBN panel, the asterisk shows a nonspecific band, bands at $55 \mathrm{kDa}$ show heavy chains of IgG and CRBN antibody, and the band at $52 \mathrm{kDa}$ shows a band for CRBN $(n=6)$ ). D, His-DJ2 (top) and His-Hsp70 (bottom) were subjected to GST pull-down assay with GST-CRBN and blotted with antibodies against DJ2, Hsp70, and CRBN $(n=3)$. $E$, CRBN binds to DJ2 but not DJ6. SH-SY5Y cells were transiently cotransfected with MycCRBN and FLAG-DJ2 or FLAG-DJ6. Cells were lysed and immunoprecipitated with mouse lgG control or $\alpha$-Myc antibody $(n=3)$. $F, G$, DJ2 and Hsp70 undergo CRBN-mediated ubiquitylation. SH-SY5Y cells were transiently transfected with HA-Ub and lysed in Ubn buffer, and IP was performed with $\alpha$-DJ2 and $\alpha$-HSP70 antibodies respectively ( $\alpha$-CRBN=Sigma). Asterisks show 
and $\mathrm{KO}\left(\mathrm{Crbn}^{-1-}\right)$ mice to assess this hypothesis. In triplicate experiments, tens of proteins with higher assigned spectra (average $>$ twofold higher) were recognized in $\mathrm{Crbn}^{-1-}$ mice versus $\mathrm{Crbn}^{+/+}$mice. Table 3 shows a list of chaperones and redox proteins filtered from the upregulated proteins as possible endogenous substrates of CRBN governing the competency of $\mathrm{Crbn}^{-1-}$ cells toward various stressors. Complete analysis is shown in Extended Data Table 3-1. Being the top-most candidate in the liquid chromatography-tandem mass spectrometry (LCMS/MS) analysis of WBL $\left(\mathrm{Crbn}^{-1-}\right.$ vs $\left.\mathrm{Crbn}^{+/+}\right)$, we anticipated that the molecular chaperone DJ2 might be an endogenous substrate of CRBN. We further analyzed the protein levels of DJ2 in various tissues of $\mathrm{Crbn}^{-1-}$ mice. Protein levels, but not the mRNA levels of DJ2, were significantly higher in most of the tissues (Fig. $1 A, B$ ). DJ2 does not function in isolation; rather, it is engaged in interaction with Hsp70 (HSPA2) as a cochaperone to stimulate the ATPase activity of Hsp70 and to deliver protein substrates. Thus, to evaluate the possibility that DJ2 and Hsp70 both are endogenous substrates of CRBN, we performed a pulldown assay to determine whether DJ2 and Hsp70 could bind to CRBN. When endogenous CRBN was immunoprecipitated, both DJ2 and Hsp70 were found to be associated with CRBN (Fig. $1 C)$. AMPK $\alpha$ was used as a positive control. Interaction of Histagged DJ2 and HSP70 with GST-tagged CRBN was further confirmed by an in vitro GST-pull down assay (Fig. $1 D$ ). It showed that DJ2 and Hsp70 can bind to CRBN individually, rather than as a complex. To rule out the possibility that the binding of CRBN to Hsp70 and DJ2 is because of the ability of chaperones to bind to versatile clients, coimmunoprecipitation (co-IP) was performed for DNAJC6 whose induction pattern was not altered in the WBL of $\mathrm{Crbn}^{-/-}$mice (Table 3). DNAJC6 did not bind to CRBN showing specific binding of CRBN to Hsp70 and DJ2 (Fig. 1E). Next, the Ubn assay was performed to confirm whether the binding of chaperones to CRBN results in their Ubn. The incorporation of HA-tagged ubiquitin into the endogenous DJ2 was completely lost in $C R B N^{-1-}$ SH-SY5Y cells (Fig. $1 F$ ), whereas it was significantly decreased for endogenous Hsp70 (Fig. 1G). Thus, DJ2 appears to be an exclusive substrate of CRBN, but other known pathways may ubiquitylate Hsp70 (Soss et al., 2015). Furthermore, FLAG-CRBN boosted the Ubn of both DJ2 and Hsp70 in vitro when cotreated with recombinant E1, E2, ubiquitin, and ATP (Fig. $1 H$, lane 5), whereas the addition of methylated ubiquitin inhibited their Ubn (Fig. $1 H$, lane 4). Since thalidomide did not interrupt the Ubn of chaperones, we did not further pursue the relationship between chaperones and IMiDs (Fig. 1I).

We next sought to test whether the knockout of CRBN would also promote chaperone accumulation in cells. Using MEF cells, we observed a delayed degradation of Hsp70 and DJ2 in the presence of CHX, a protein synthesis inhibitor (Fig. 1J), in $\mathrm{Crbn}^{-1-}$ MEF cells. On the other hand, these chaperones significantly

$\leftarrow$

nonspecific bands ( $n=5$ ). $\boldsymbol{H}$, SH-SY5Y cells were transiently transfected with FLAG-CRBN and immunoprecipitated with Flag M2 agarose beads. In vitro ubiquitylation of endogenous, coprecipitated DJ2 and Hsp70 was conducted in the presence of E1 + E2 and Ub. Me-Ub was added where indicated $(n=5)$. I, SH-SY5Y cells were treated with thalidomide (500 nm) for $24 \mathrm{~h}$, then transiently transfected with $\mathrm{HA}$-Ub (in the presence of thalidomide), and ubiquitylation assay was performed. J, $\boldsymbol{K}$, DJ2 and HSP70 are accumulated in $\mathrm{Crbn}^{-1-}$ cells. WT $\left(\mathrm{Crbn}^{+/+}\right)$and $\mathrm{KO}\left(\mathrm{Crbn}^{-1-}\right)$ MEF cells were treated with $2.5 \mu \mathrm{g} / \mathrm{ml} \mathrm{CHX}$ or $0.5 \mu \mathrm{g} / \mathrm{ml}$ MG132, respectively, and harvested at the indicated time points $(n=6) .{ }^{*} p<0.05$, ${ }^{* *} p<0.01$, and ${ }^{* * *} p<0.001$; Student's $t$ test was used to calculate the $p$ value for WT and $\mathrm{KO}$ cells at the time points mentioned. accumulated on treatment with MG132, a proteasome inhibitor (Fig. $1 K$ ). These results indicate that $\mathrm{Hsp} 70$ and DJ2 are endogenous substrates of CRL4 ${ }^{\mathrm{CRBN}}$ for Ubn and are degraded by the proteasome.

\section{The C-terminal extension of DJ2 is required for its CRBN- dependent Ubn}

To locate the amino acid sequence in DJ2 recognized by CRBN, a series of deletion mutants was constructed for both HA-tagged CRBN (HA-CRBN) and Myc-tagged DJ2 (Myc-DJ2; Fig. 2A,C). Pull-down assays showed that a stretch of $\sim 80$ aa at the $\mathrm{N}$ terminus of CRBN (Lon-N) interacts with a span of $\sim 100$ aa at the $C$ terminus of DJ2 (Fig. $2 B, D$ ). To pinpoint the sequences in DJ2 and $\mathrm{CRBN}$ that are crucial for their interaction, we generated additional deletion mutants of both proteins (Fig. $2 E, G$ ), which showed the indispensability of a " $\beta$-turn- $\beta$ " loop joining the $\beta 3$ and $\beta 4$ of CRBN and a span of 40 aa at the $C$ terminus of DJ2 (Fig. $2 F, H$ ). We then analyzed several structural models of DJ2 docked onto CRBN, with the $3 \mathrm{D}$ coordinates of all the atoms defined using ClusPro (Kozakov et al., 2017), a fully automated algorithm for protein-protein docking. For the computational analysis, PDB files of the crystal structure of CRBN (4TZ4) and structural model of DJ2 generated by I-TASSER server (Yang et al., 2015) were used (Fig. 2I). Based on the in vitro co-IP results and computational docking analysis, we engineered mutations in 6 aa (T279 T284) of DJ2 and 2 aa of CRBN (E152 and F153) either individually or in combination. For CRBN, mutations of E152 and F153 to alanine (Ala or A) disrupted its binding ability, signifying a role for these residues in the interaction of CRBN with DJ2 (Fig. 2J). In the case of DJ2, the Ala mutations of four residues (D281A, N282A, R283A, and T284A) resulted in a significant loss of the binding capability to $\mathrm{CRBN}$, indicating that these residues may play a critical role in the binding of DJ2 to CRBN (Fig. 2K).

\section{Lys32 and Lys350 are the major ubiquitination sites in DJ2}

Since DJ2 is heavily ubiquitinated on the transfection of exogenous ubiquitin (Fig. $1 F$ ), we sought to identify the lysine residues targeted by CRL4 ${ }^{\text {CRBN }}$ for Ubn. According to PhosphoSitePlus (Hornbeck et al., 2012), a comprehensive database of experimentally observed mammalian post-translational modifications, the lysine residues that undergo Ubn are accumulated mainly in the J-domain and C-terminal domain in DJ2 (Fig. 3A). We substituted these lysine residues individually with arginine and performed the Ubn assay in SH-SY5Y cells (Fig. 3B). The K32R and K350R mutants exhibited delayed degradation in the CHX-chase assay (Fig. 3C,D). A double mutant, K32R/K350R, demonstrated an almost complete loss of Ubn, with significant accumulation in the cells, compared with WT-DJ2 (Fig. 3E). Collectively, these findings suggest that $\mathrm{K} 32$ and $\mathrm{K} 350$ in DJ2 are the major Ubn sites ubiquitylated by CRL $4^{\mathrm{CRBN}}$, leading to its degradation. Ubn details of Hsp70 have already been well characterized previously (Soss et al., 2015).

Effects of CRBN and DJ2 on tau fibrillation and interactions The anti-tau activity of DJ2 was reported previously, suggesting the ubiquitin-dependent clearance of tau (Abisambra et al., 2012), but its chaperone activity has not yet been uncovered. We speculated that the chaperone activity of DJ2 may decrease the recruitment of cytosolic tau onto the ends of fibrillar tau, known as the template-assisted conversion of tau monomers into fibril (Liu et al., 2012). To provide evidence for this hypothesis, we performed an in vitro aggregation assay with the following three 


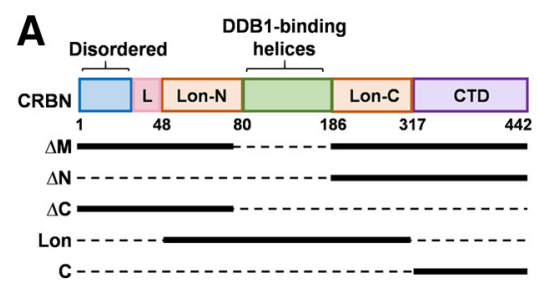

C

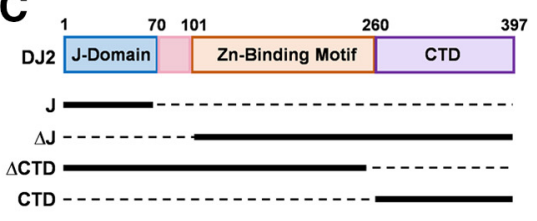

E

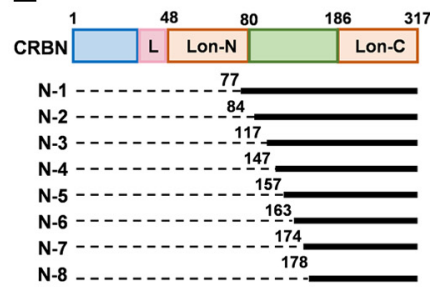

$\mathbf{G}_{176}$

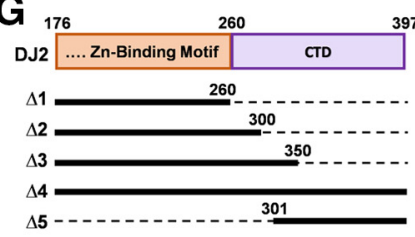

B

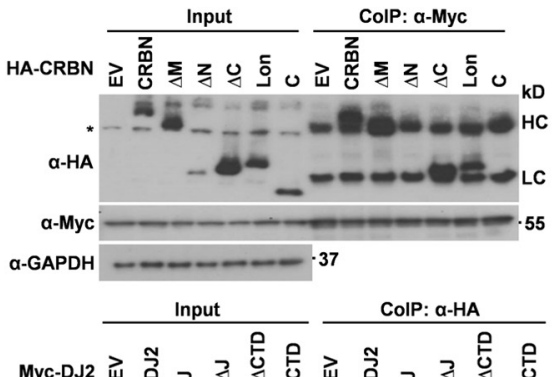

HA-CRBN - + + + + + + + + + ++

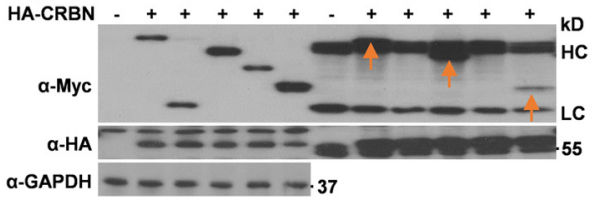

F

Input

ColP: a-Myc
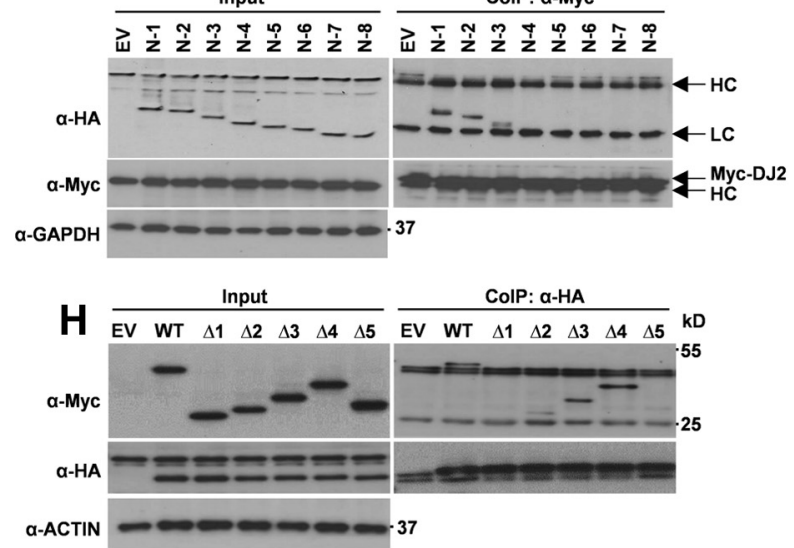

I
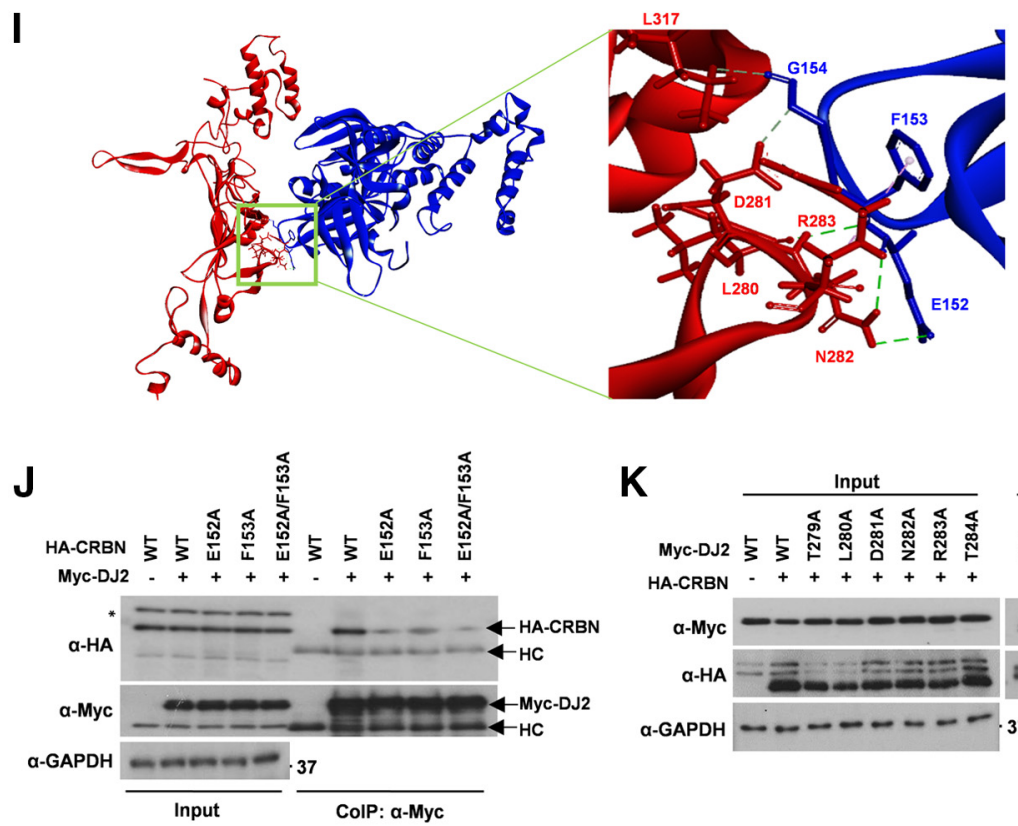

K

Input

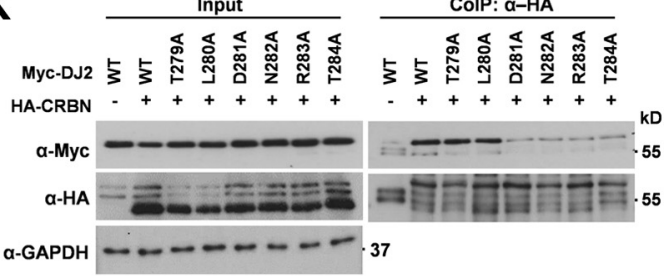

Figure 2. The N-terminal Lon domain of CRBN binds to the C-terminal domain of DJ2. $\boldsymbol{A}, \boldsymbol{C}$, Schematic diagram of the rCRBN and $\mathrm{hDJ} 2$ constructs used in $\boldsymbol{B}$ and $\boldsymbol{D}$ with HA and Myc tags, respectively. L, Linker; CTD, C-terminal domain; Lon-N, N-terminal Lon domain; Lon-C, C-terminal Lon domain. $\boldsymbol{B}, \mathbf{D}, \mathrm{SH}-\mathrm{SY} 5 \mathrm{Y}$ cells were transiently cotransfected with the genetic constructs indicated. After $24 \mathrm{~h}$, cellular extracts were immunoprecipitated with the antibodies mentioned. A band at $\sim 55 \mathrm{kDa}$ represents lgG heavy chains (HC), and at $\sim 25 \mathrm{kDa}$ represents lgG light chains (LC). Asterisk (*) indicates a nonspecific band $(n=3)$. $\boldsymbol{E}, \boldsymbol{G}$, Schematic diagram of the deletion-mutant constructs of rCRBN and hDJ2 used in $\boldsymbol{F}$ and $\boldsymbol{H}$ with HA and Myc tags, respectively. $\boldsymbol{F}$, $\boldsymbol{H}$, SH-SY5Y cells were transiently cotransfected with the genetic constructs indicated. After $24 \mathrm{~h}$, cellular extracts were immunoprecipitated and blotted with the antibodies mentioned ( $n=3$ ). $I$, Structural model of DJ2-CRBN interaction predicted by ClusPro, a fully automated algorithm for protein-protein docking. A number of structural models of DJ2 docked onto the CRBN were analyzed using ClusPro. PDB files of the crystal structure of CRBN (4TZ4) and structural model of DJ2 generated by the I-Tasser server were used. This binding mode was selected after combining the docking data with co-IP data. J, E152 and F153 of CRBN are critical for the binding of CRBN to DJ2. SH-SY5Y cells were transiently cotransfected with Myc-DJ2 and the indicated plasmids. After $24 \mathrm{~h}$, cellular extracts were immunoprecipitated with $\alpha$-Myc antibody. A band at $\sim 55 \mathrm{kDa}$ represents lgG HCs and the asterisk indicates a nonspecific band. $n=5$. $\boldsymbol{K}$, Four residues of DJ2 (D281-T284) are critical for the binding of DJ2 to CRBN. SH-SY5Y cells were transiently cotransfected with HA-CRBN and indicated plasmids. IP was performed with the HA antibody after $24 \mathrm{~h}(n=5)$. 
A

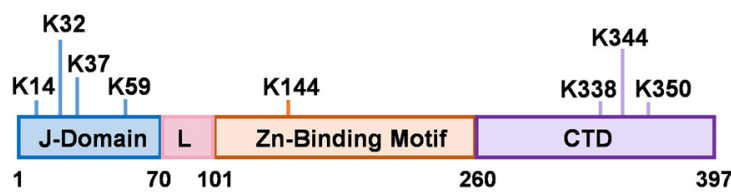

B

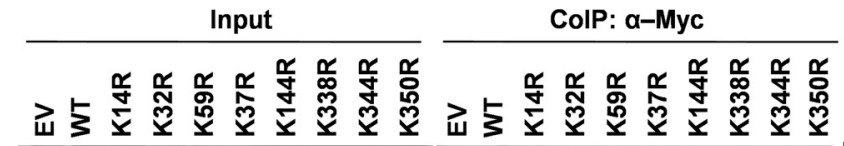

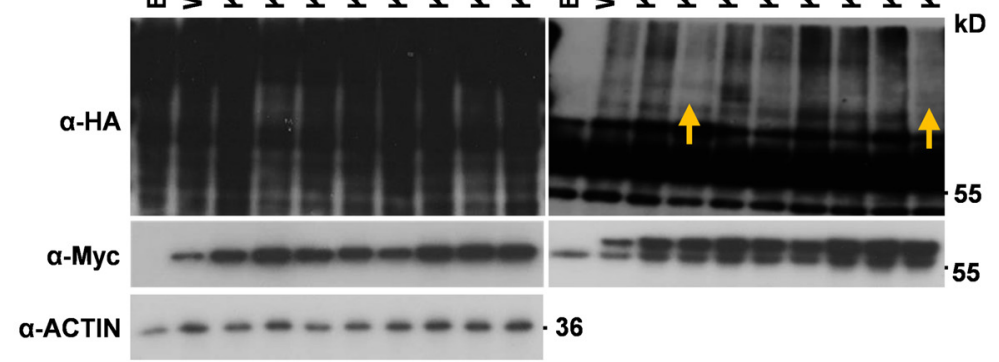

C
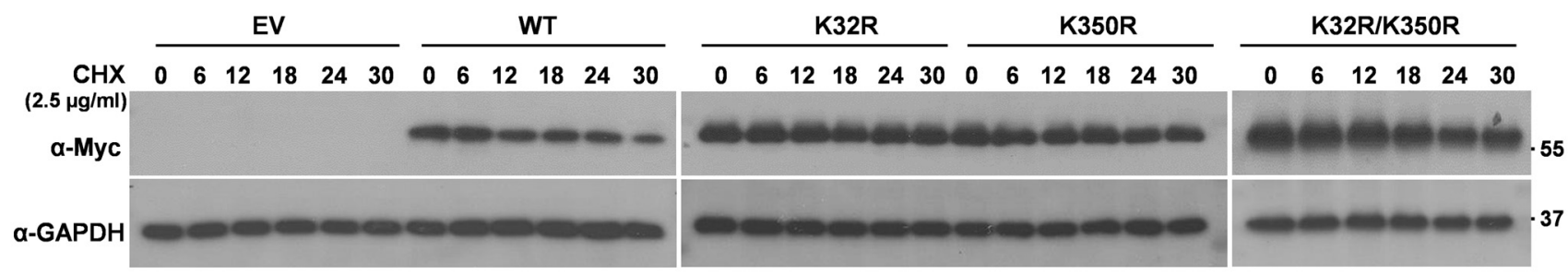

D

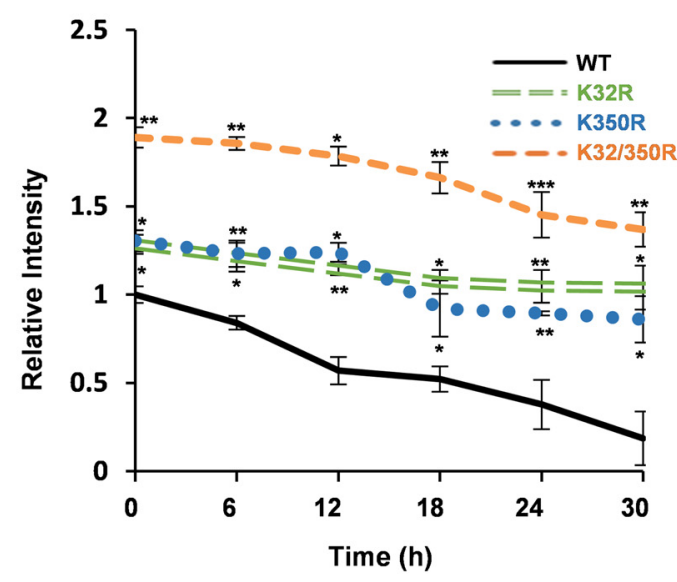

$\mathbf{E}$

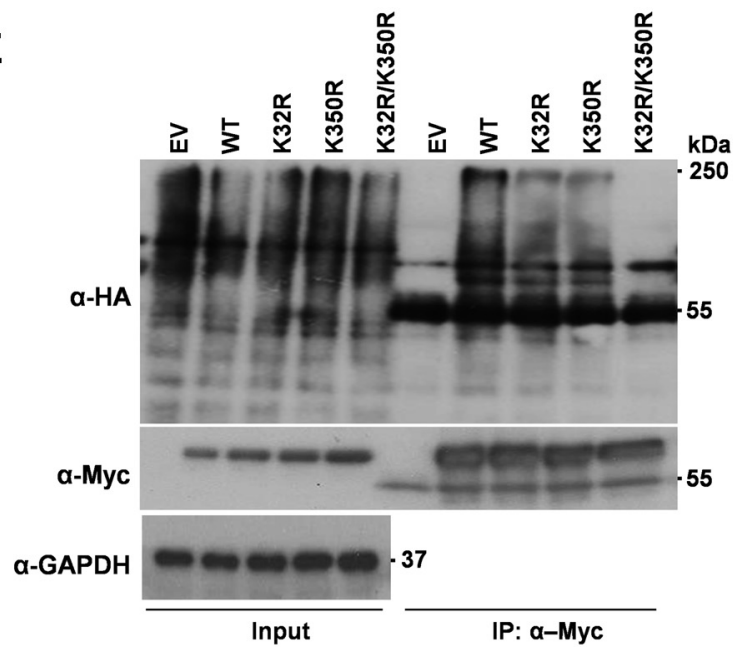

Figure 3. Localization of specific lysine residues responsible for the ubiquitination of DJ2. A, J-domain and C-terminal domain of DJ2 accommodate most of the Ubn sites. The PhosphositePlus and GGbase databases were used to identify the experimentally reported lysines that are ubiquitinated in DJ2. B, K32 and K350 are the major ubiquitination sites in DJ2. SHSY5Ycells were transfected with EV, WT DJ2, or various lysine mutants. HA-Ub was cotransfected. The Ubn assay was performed as described in Figure $1 F(n=5)$. C, D, SH-SY5Ycells were transfected with EV, WT DJ2, or lysine mutants. Cells were treated with $2.5 \mu \mathrm{g} / \mathrm{ml} \mathrm{CHX}$ and harvested at the indicated time points for immunoblot analysis. Equal amounts of cell lysates were examined by SDS-PAGE and probed with the specified antibodies. The relative ratio of DJ2/GAPDH protein level, normalized to that at zero time, is shown. ${ }^{*} p<0.05$, ${ }^{* *} p<0.01$, and ${ }^{* * *} p<0.001$. Student's $t$ test was used to calculate $p$ values for WT and KO cells at the time points mentioned from five independent experiments. E, SH-SY5Ycells were transfected with EV, WT DJ2. or lysine mutants along with HA-Ub. Cells were harvested after $24 \mathrm{~h}$, and Ubn assay was performed.

different forms of tau: (1) Alzheimer-like PHF of tau (aggregation time, 7-9 d); (2) full-length tau (aggregation time, $\sim 20-40$ h); and (3) truncated tau (repeat domain of tau or K18) with faster kinetics (aggregation time, $\sim 3-4 \mathrm{~h}$ ), in the presence of chaperones and CRBN in different combinations. Chaperones alone or in different combinations were incubated with tau in the absence of heparin as a positive control experiment (Fig. $4 A$ ). Incubation of tau species with chaperones reduced their heparinmediated fibrillation, as shown by reduced binding of the ThT dye (Fig. $4 B-D$ ). Hsp70 alone could not ablate the aggregation of tau as efficiently as DJ2. On the other hand, the sequestration of DJ2 by CRBN reduced its activity to prevent tau aggregation. Tau and K18 aggregates prepared in the presence of DJ2 were not toxic when added to SH-SY5Y extracellularly (Fig. $4 E, F$ ). These results show a CRBN-dependent and Hsp70-independent role of DJ2 toward tau aggregation, possibly by holding and stabilizing the intrinsic state of tau.

Since decreased binding of ThT dye suggests fewer tau fibrils and does not preclude the possibility of amorphous nonfibrillar tau, we next sought to examine the effect of CRBN on tau-tau interaction driven by tau phosphorylation. To this end, we used the Venus-based BiFC technique (Lim et al., 2014), as shown schematically in Figure 5A. SH-SY5Y cells [WT $\left(C R B N^{+/+}\right)$, KO $\left(C R B N^{--}\right)$and $\mathrm{KO}\left(C R B N^{--}\right)$having DJ2 knocked down; Fig. $5 B]$ were transiently transfected with BiFC-EV (control) and $\mathrm{BiFC}$-tau constructs and treated with $\mathrm{OA}$, a serine/threonine 

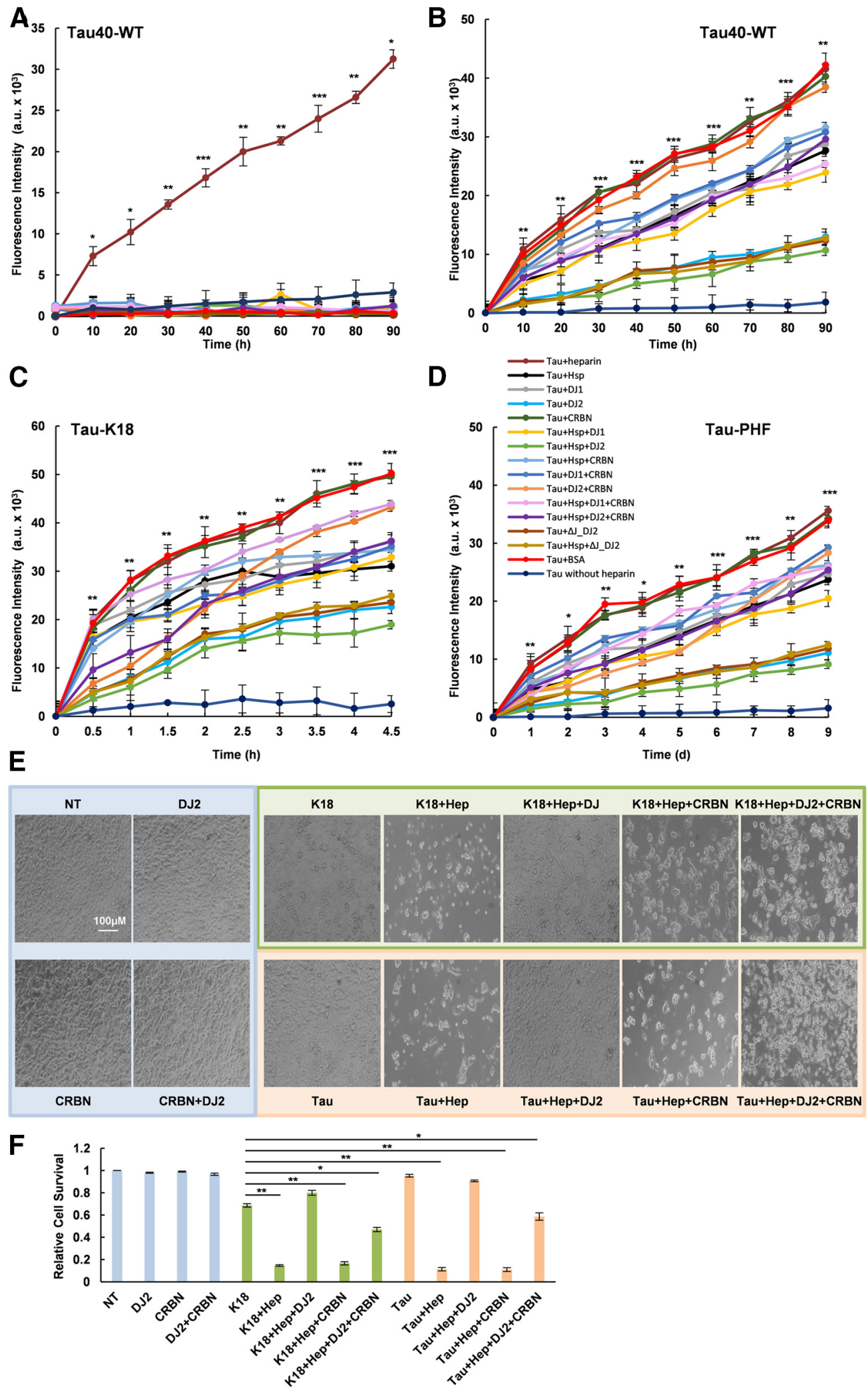

Figure 4. Chaperone activity of DJ2 prevents template-assisted aggregation of tau. A, Full-length $\mathrm{hTau}-40(5 \mu \mathrm{m})$ was incubated at $37^{\circ} \mathrm{C}$ with the indicated combinations of proteins $(5 \mu \mathrm{M})$ for $90 \mathrm{~h}$, all without heparin (control experiment) except the one mentioned (Tau + heparin, maroon line). Samples were collected at the time points mentioned and kept at $-80^{\circ} \mathrm{C}$ until the collection of all samples. ThT $5 \mu \mathrm{m}$ was added after $90 \mathrm{~h}$ to observe the degree of aggregation and fluorescence emission that was measured at $480 \mathrm{~nm}$, with excitation at $440 \mathrm{~nm}$. Student's $t$ test and one-way ANOVA was used for the statistical analysis of data. Experiments were repeated three times with three samples $(n=9)$ for all data points. Labels and colors shown in the inset of $\boldsymbol{D}$ are also applicable for all other panels $(\boldsymbol{A}-\boldsymbol{C})$. $p$ Values shown here are calculated for "tau + heparin" with respect to zero time point. Statistical analysis of different combinations with respect to "tau without heparin" and "tau with heparin" is shown in Extended Data Figure 4-1. B, Experiment detailed in $\boldsymbol{A}$ was repeated with heparin added to all the samples, except the negative control. Heparin was included in all the reactions except the negative control (tau without heparin, orange line), at a concentration of $2.5 \mu \mathrm{m}$. Student's $t$ test and one-way ANOVA were used for the statistical analysis of data (Extended Data Figure 4-1). The experiment was repeated five times with three samples $(n=15)$ for all data points in every experiment. C, 
phosphatase inhibitor to induce tau phosphorylation (Baker and Götz, 2016). Strong fluorescence was detected in most WT cells because of hyperphosphorylation-induced tau dimerization (Fig. $5 C$, second panel from left, bottom row). This effect was greatly decreased in $\mathrm{KO}$ cells (Fig. 5C, third panel, bottom row). As expected, a knockdown of DJ2 resulted in the increased BiFC fluorescence even in the absence of OA (Fig. $5 C$, last panel, bottom row). Phosphorylation status of tau was confirmed through Western blot analysis as well (Fig. 5D). These results strongly suggest that the depletion of CRBN decreases the phosphorylation-mediated interactions of tau presumably because of the elevated chaperone activity of DJ2.

Tau regulates the architecture of the microtubule array. Therefore, it was important to elucidate the effect of CRBN on the partitioning of tau from an amorphous form to a fibrillar, cytotoxic form. To this end, $C R B N^{+/+}$and $C R B N^{-/-} \mathrm{SH}-$ SY5Ycells were treated with OA to induce tau phosphorylation and progressive detachment from microtubules (Gong et al., 2000). As shown in Figure $5 E$, treatment of $C R B N^{+/+}$cells with OA results in an increase in the cytoplasmic pool of tau. On the contrary, $C R B N^{-1}$ cells showed an improved colocalization of tau with microtubules before and even after treatment with OA. Hence, overexpression of DJ2 increases the affinity of tau for microtubules explaining the phenotype resulting from OA treatment.

\section{Attenuation of CRBN promotes the chaperone activity of DJ2}

An inverse relation between tau and DJ2 has been reported previously in the cell-based system (Abisambra et al., 2012). However, tau expression did not change in the MS/MS analysis of WBL of $\mathrm{Crbn}^{-1-}$ mice, although the DJ2 level was markedly increased. To reveal the role of CRBN here, we established a cellbased system by genetically depleting CRBN from the cells, thus increasing the activity of DJ2. Blunted phosphorylation of tau was observed when the CRBN locus was disrupted by CRISPR/ Cas9 in an HEK293 cell line overexpressing Myc-tau transiently (Fig. 6A, tau panel). In $C R B N^{+/+}$cells, Hsp70 as well as DJ2 showed an inverse relationship with tau, but not in the $C R B N^{-1-}$ cell line (Fig. $6 A$, chaperones panel). One possible reason for the inverse relation between tau and DJ 2 could be a CRL $4^{\text {CRBN }}$ mediated degradation of tau. To confirm this, the Ubn assay was performed for endogenous and exogenous tau. Interestingly, Ubn of tau declined when CRBN was knocked down in SHSY5Y cells (Fig. 6B). Furthermore, this Ubn depends on the binding of tau to DJ2, as tau did not show any direct binding to

\footnotetext{
$\leftarrow$

Using hTau-K18 mutant, experiment detailed in $\boldsymbol{A}$ was repeated with heparin added to all the samples, except the negative control. hTau-K18 $(5 \mu \mathrm{m})$ was incubated at $37^{\circ} \mathrm{C}$ for $4 \mathrm{~h}$. One-way ANOVA was used for the statistical analysis of data. The experiment was repeated five times with three samples $(n=15)$ for all data points in every experiment. $\boldsymbol{D}$, To monitor the effects of chaperones on Alzheimer-like PHF formation, experiment detailed in $\boldsymbol{A}$ was repeated with full-length hTau- $40(5 \mu \mathrm{M})$. Samples were incubated at $37^{\circ} \mathrm{C}$ with the indicated combinations of proteins $(5 \mu \mathrm{m})$ for $9 \mathrm{~d}$, with heparin added to all the samples, except the negative control. One-way ANOVA was used for the statistical analysis of data. Experiment was repeated five times with three samples $(n=15)$ for all data points in every experiment. Complete statistical analysis of $\boldsymbol{A}-\boldsymbol{D}$ is shown in Extended Data Figure 4-1. $\boldsymbol{E}$, SH-SY5Y cells were treated with monomeric and aggregated forms of hTau-K18 (top panel) and full-length hTau-40 (bottom panel) with or without DJ2 and CRBN as shown. $\boldsymbol{F}$, MTT assay was performed after $48 \mathrm{~h}$ to assess cell viability. Error bars represent the SEM. Student's $t$ test was used for quantification of data with a 95\% significance level in Excel $(n=3)$. ${ }^{*} p<0.05$, ${ }^{* *} p<0.01$, and ${ }^{* * *} p<0.001$.
}

CRBN, but did to DJ2 (Fig. 6C,D). Thus, an exogenous rise of DJ2 in the $C R B N^{+/+}$system may decrease the tau levels by enhancing the DJ2-mediated Ubn and degradation of tau by CRL4 ${ }^{\mathrm{CRBN}}$, whereas in the $C R B N^{-/-}$system, the chaperone activity of DJ2 may be more profound since there is no recruitment of DJ2 and tau for degradation.

\section{CRBN tunes the chaperone activity of DJ2 to prevent tau phosphorylation and tau pathology}

Since DJ2 alone can prevent the misfolding of tau protein in a cell-free condition, we pursued our further studies to find out the effect of DJ2 in ablating tau phosphorylation and the interference caused by CRBN in vivo. To this end, we compared the levels of phosphorylation at different sites of tau in the WBL of WT $\left(\mathrm{Crbn}^{+/+}\right)$and $\mathrm{KO}\left(\mathrm{Crbn}^{-1-}\right)$ mice. For most of the sites, the basal level of tau phosphorylation was considerably reduced in WBL of $\mathrm{Crbn}^{-1-}$ mice (Fig. $7 \mathrm{~A}$ ). Cryosectioning revealed the same results for phosphorylation status of tau and enhanced levels of DJ2 in the hippocampal and cortical regions (Fig. 7B). To find out whether the decrease in tau phosphorylation is a consequence of the increased chaperone activity of DJ2 alone, or the activity of tau kinases is also compromised, we further measured the active forms of tau kinases in WBL. Intriguingly, phosphorylation at Ser9 and Ser21 of GSK-3 $\alpha / \beta$ was found to be significantly increased in $\mathrm{Crbn}^{-1-} \mathrm{WBL}$, showing that its enzymatic activity was reduced (Fig. $7 C$ ). Likewise, the kinase activities of ERK1/2 and p38 were found to be reduced, as shown by a decrease in their phosphorylated forms (Fig. 7C). To corroborate whether the compromised activation of tau kinases is a specific consequence of either CRBN knockout or an abundance of DJ2, SH-SY5Y cells were transfected with exogenous DJ2. Interestingly, the phosphorylation of tau was decreased with the overexpression of DJ2 without affecting the activation of tau kinases (Fig. 7D), suggesting the role of DJ2 in limiting the phosphorylation of tau by decreasing its recruitment to tau kinases. Thus, our results indicate that both increased chaperone activity and compromised tau kinase activity maintain the basal level of tau phosphorylation in $\mathrm{Crbn}^{-1-}$ mice.

\section{Effects of CRBN depletion on the accumulation of pathologic tau in the brain}

Pathologic tau induces disruption of the synapses, which is a common hallmark of aging and progressive neurodegeneration, with a subsequent massive loss of neurons (Shimojo et al., 2020). We compared the progression of pathologic tau in young (1month-old) and aged (15-month-old) mice using AT8 antibody, which can stain, for example, various types of tangles, pretangles, and flame tangles, and phosphorylation at Ser202/Thr205. As expected, $\mathrm{Crbn}^{-1-}$ mice showed a marked decrease in the phosphorylation of tau at Ser202/Thr205 as well as in AT8 staining (Fig. 8A,B).

Local insult with OA can promptly induce phosphorylation and aggregation of tau at anatomically distant regions of the brain by inhibiting protein phosphatase 2A (Baker and Götz, 2016). We used this strategy to verify the competence of $\mathrm{Crbn}^{-1-}$ mice toward the accumulation of phosphorylated tau in different regions of the brain. As published previously (Baker and Götz, 2016), we used a single and very low dose of OA (10 ng). Second, through using a low volume $(130 \mu \mathrm{l})$, we aimed to ensure specific OA exposure and avoid spillover. The coordinates were selected to ensure the prevention of OA passing through the ventricle or the hippocampal formation. OA was stereotaxically injected into the brains of 8-month-old mice, and tau phosphorylation levels 
A

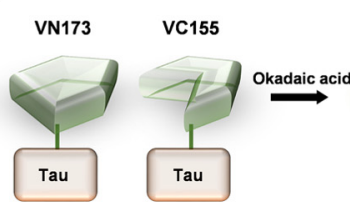

VENUS

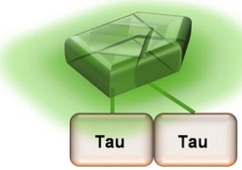

B

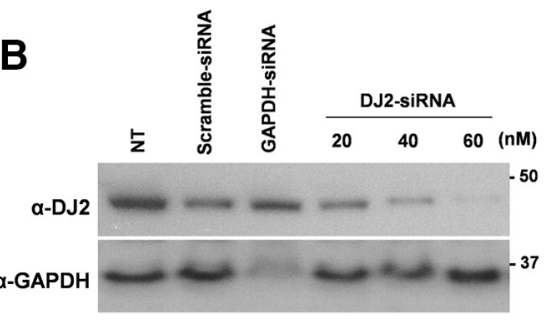

C
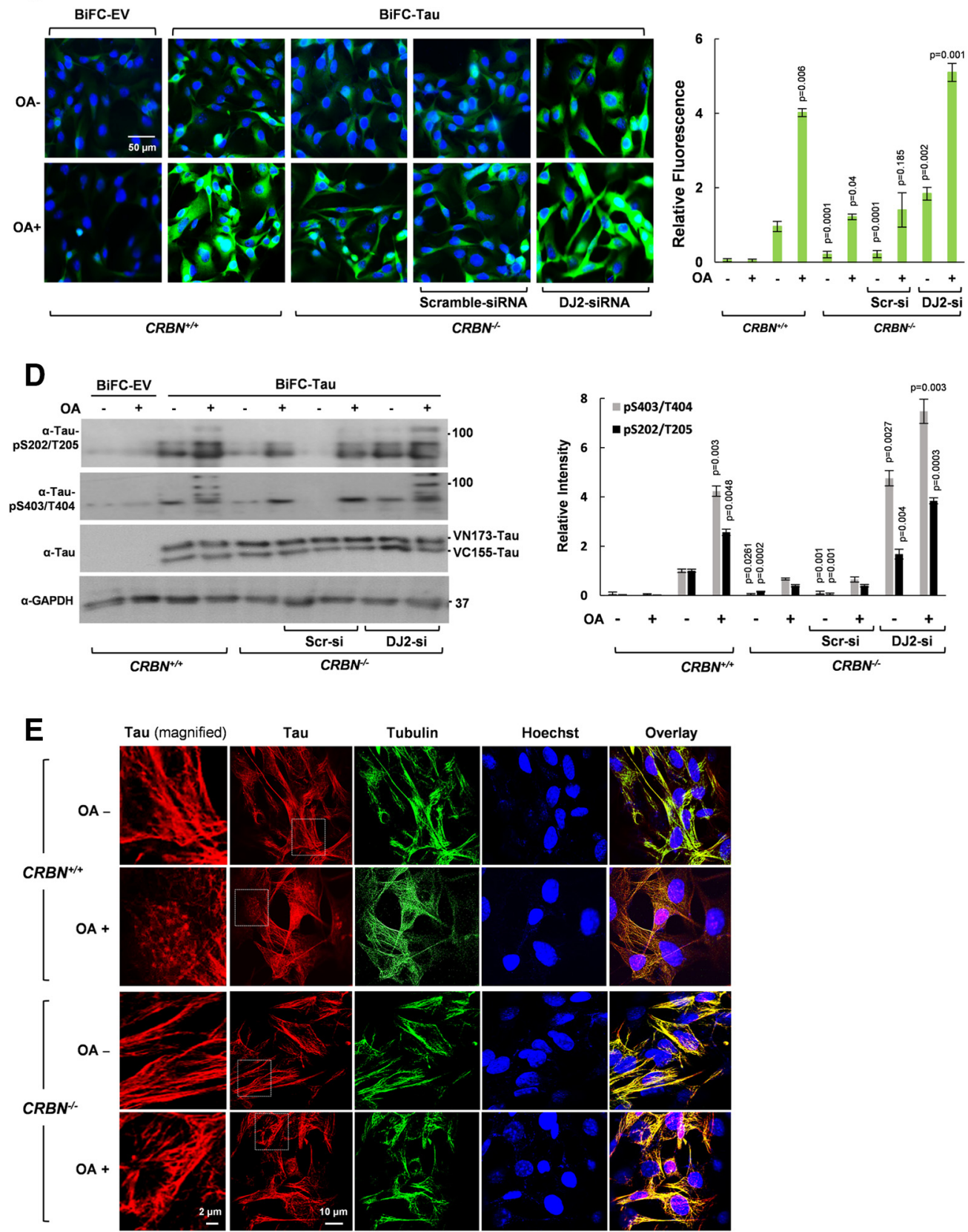

Figure 5. Knocking out CRBN improves the association of tau with microtubules by decreasing tau phosphorylation. $\boldsymbol{A}$, Schematic representation of the BiFC assay. $\mathrm{hTau}-40$ is attached to nonfluorescent N- or C-terminal fragment of Venus fluorescence protein (VN173 or VC155). The Venus fluorescence turns on only when the phosphorylated tau assembles. $\boldsymbol{B}$, CRBN ${ }^{+/+}$and $C^{2} B N^{-1-}$ SH-SY5Y cells were transfected with siRNA targeting DJ2 to find out the optimal conditions for knockdown of DJ2. siRNA targeting GAPDH was used as positive control $(n=4)$. $C$, Effects of CRBN on phosphorylation-mediated tau dimerization. CRBN ${ }^{+/+}$and $C R B N^{-1-}$ SH-SY5Y cells were transfected withVN173 and VC155 empty vectors (BiFC-EV) or VN173-tau and VC155-tau (BiFC-tau) constructs and treated with OA (30 nm). (RBN ${ }^{-1-}$ SH-SY5Y cells transfected with siRN-DJ2 were also used (bottom panel). Hoechst dye was used as a counterstain. Cells were imaged under fluorescence microscope $(n=5)$. $\boldsymbol{D}$. Cells from $\boldsymbol{C}$ were subjected to Western blot analysis. ImageJ was used to quantify the fluorescence Intensity and Western blots, and is represented as the mean \pm SD $(n=5)$. Scr-si, Scramble siRNA; DJ2-si, DJ2 siRNA. Student's $t$ test was used to calculate statistical significance. $E$, CRBN ${ }^{-/-}$(KO) and CRBN ${ }^{+/+}$(WT) HEK293 T cells were treated with $\mathrm{OA}$ for $16 \mathrm{~h}$ and stained with tubulin tracker green, tau antibody (secondary antibody Alexa Fluor-594), and Hoechst dye. The cells were then imaged with an FV1000 confocal laser-scanning microscope $(n=5)$. 

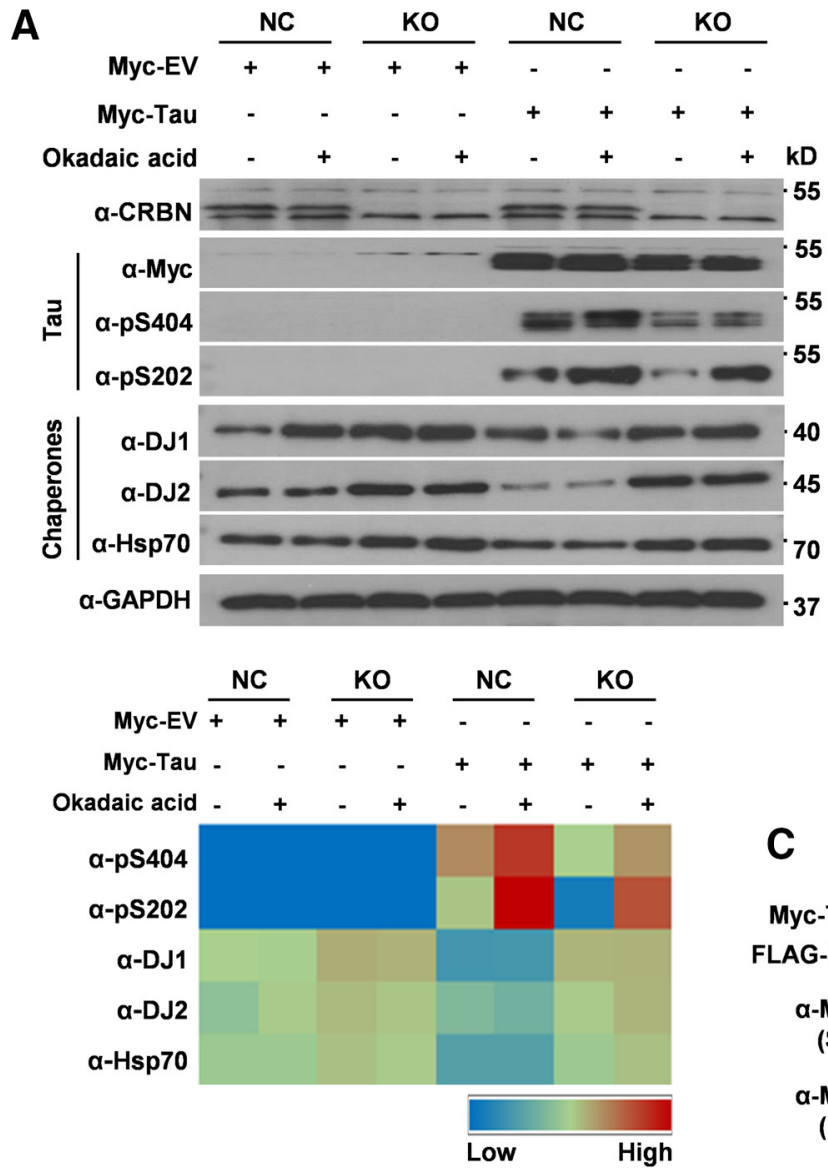

B
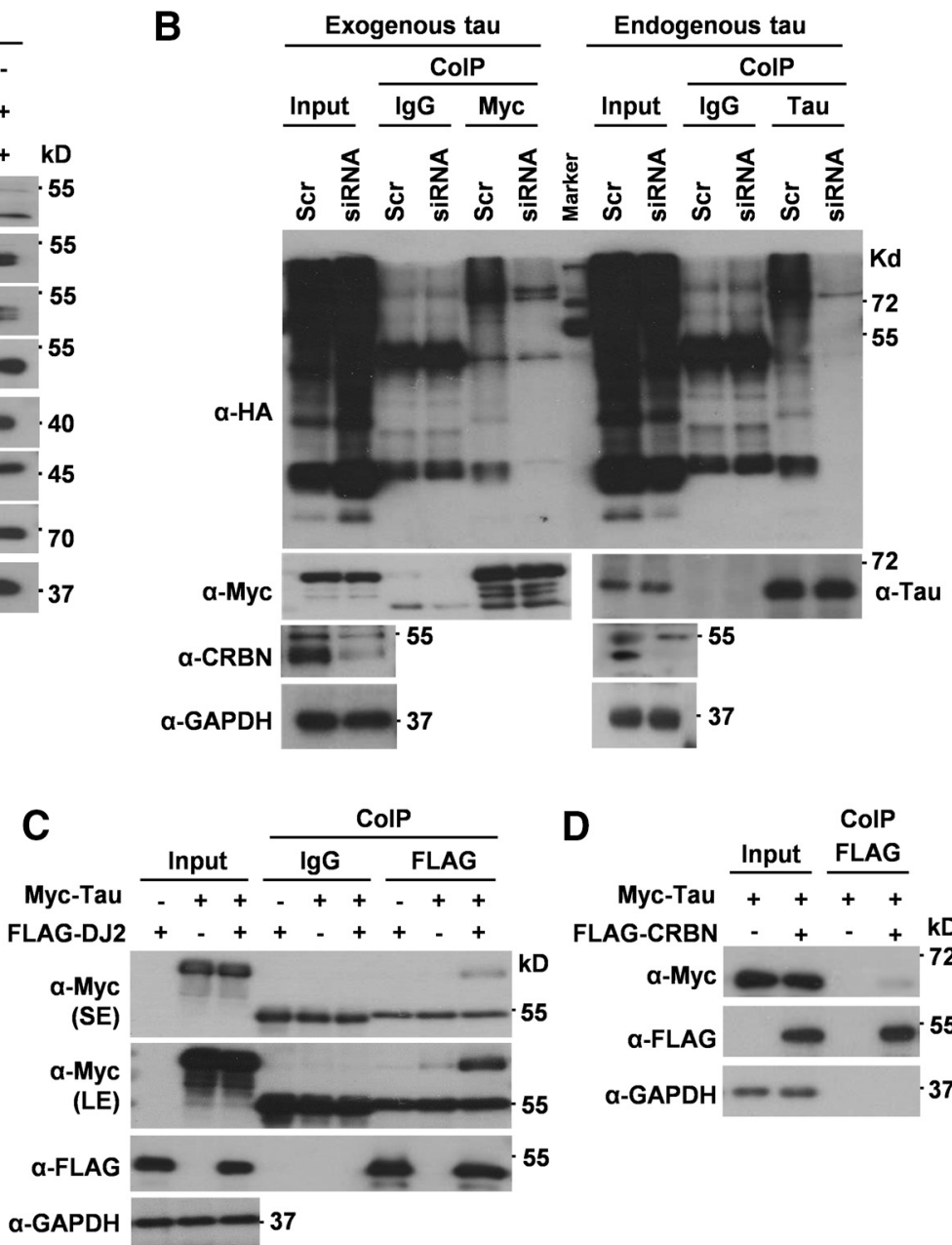

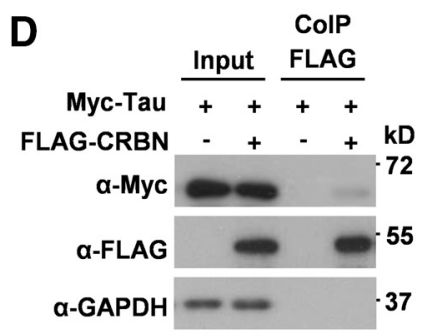

Figure 6. CRBN tunes the chaperone activity of DJ 2 to prevent tau phosphorylation and tau pathology. $\boldsymbol{A}$, HEK293T cells were subjected to CRISPR/Cas9-mediated K0 of CRBN or nontargeting gRNA sequences [negative control (NC) vector]. $\boldsymbol{B}$, Myc-tau was transiently transfected to both cell lines, and Western blot was performed against the pathologic phospho-tau sites (tau panel) and chaperones (chaperone panel). Heat map shows the statistical analysis of five independent experiments, whereas the intensity of each box shows the mean value $(n=5)$. $\mathbf{C}$, $\mathbf{S H}$ SY5Y cells were transiently cotransfected with Myc-tau and FLAG-DJ2, and immunoprecipitated with mouse lgG or $\alpha$-FLAG antibody, SE (short exposure), and LE (long exposure). D, SH-SY5Y cells were transiently cotransfected Myc-tau and FLAG-CRBN; and immunoprecipitated with $\alpha$-FLAG antibody $(n=3)$.

were analyzed $24 \mathrm{~h}$ and $7 \mathrm{~d}$ postinjection (Fig. $8 C-F$ ). Although a substantial rise in tau phosphorylation was observed at multiple sites (e.g., pT181, pT231, and pS403/404) in $\mathrm{Crbn}^{+/+}$brains, it was significantly prevented in both hemispheres of $\mathrm{Crbn}^{-1-}$ brains $24 \mathrm{~h}$ postinjection (Fig. $8 D$ ). Inhibition of GSK3 $\alpha / \beta$ with higher levels of phosphorylation was more noticeable in $\mathrm{Crbn}^{-1-}$ mice than in $\mathrm{Crbn}^{+/+}$mice (Fig. $8 E, 24 \mathrm{~h}$ postinjection). Observations were almost consistent even after $7 \mathrm{~d}$ of OA injections (Fig. $8 F$ ). These results strongly suggest that the absence of CRBN can elicit resistance to the aggregation and accumulation of pathologic tau, since hyperphosphorylated tau can induce nucleation-dependent aggregation in a localized fashion in tauopathies (Goedert et al., 2017). Statistical analysis of Figure $8 D-F$ is shown in Figure 9.

The suppressed activity of DJ2 in murine models of neuropathy

Next, we set out to investigate the contribution of CRBN and DJ2 to the development and progression of disease in murine models of neuropathy. Amyloid- $\beta$ (A $\beta$ ) plaques are one of the tauopathy triggering factors as they enhance the development of tau pathology through the increased spreading of pathologic tau (Vergara et al., 2019). To figure out whether CRBN is also a tauopathy-inducing factor, we analyzed the brain samples from 8-month-old 5XFAD and APP ${ }^{\mathrm{NL}-\mathrm{G}-\mathrm{F}}$ knock-in mice as they exhibit a late onset of tauopathy. The presence of $\mathrm{A} \beta$ plaques was confirmed in the brain samples of 5XFAD and APP ${ }^{\text {NL-G-F }}$ knock-in mice through immunostaining with APP antibody (Fig. 10A). Hippocampi of 8-month-old mice were immunolabeled with CRBN and DJ2 antibodies. As expected, elevated expression of CRBN was observed in the hippocampus and cortical regions of 5XFAD and $\mathrm{APP}{ }^{\mathrm{NL}-\mathrm{G}-\mathrm{F}}$ knock-in mice as confirmed by immunohistochemistry and Western blot (Fig. 10B,C). On the other hand, chaperone levels were also significantly low for the same regions (Fig. 10C). This shows that elevated CRBN is an influential factor for tauopathies. Thus, CRBNmediated attenuation of chaperone activity can be an additional mechanism of Alzheimer's disease that warrants therapeutic emphasis.

Considering the substantial consequences of CRBN-DJ2 interaction, we pursued the rational design of a peptide inhibitor based on the hotspot region of DJ2 that interacts with CRBN (Fig. 2I). Cysteine residues were added to both ends to circularize the peptide (Fig. 10F). It was done to attain the conformation required for the interaction of the DJ2 loop to the CRBN (Fig. 2I). A $10 \mu \mathrm{M}$ concentration of peptide inhibitor completely 

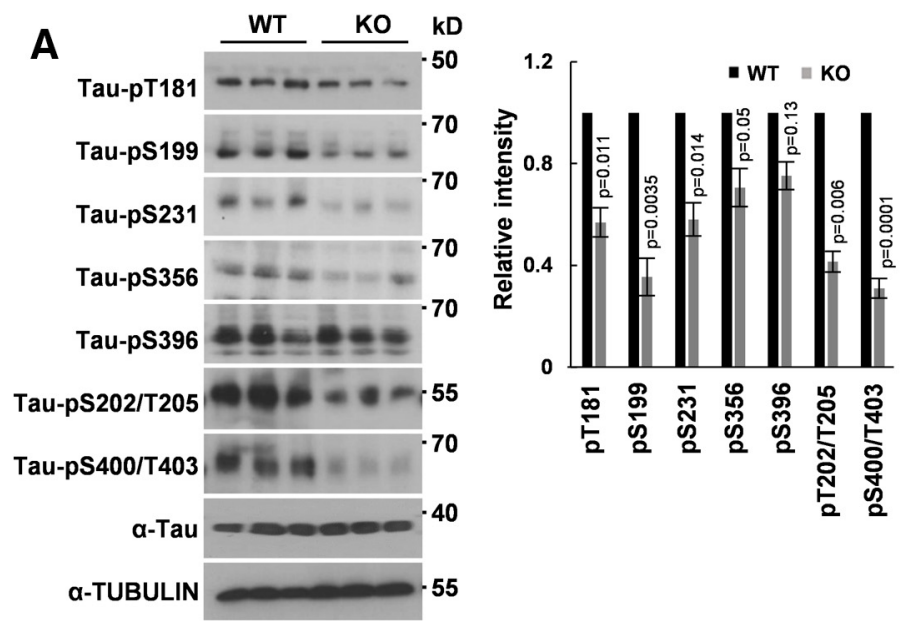

B
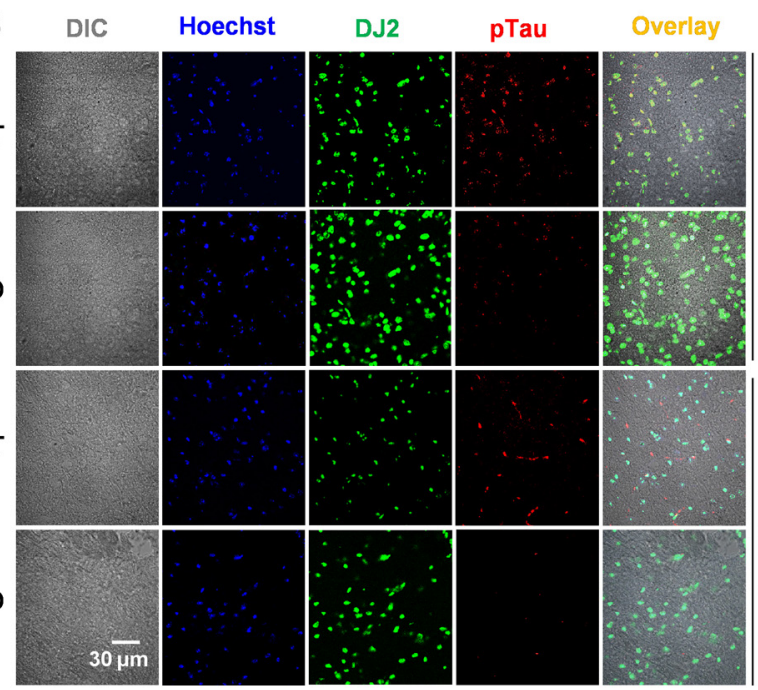
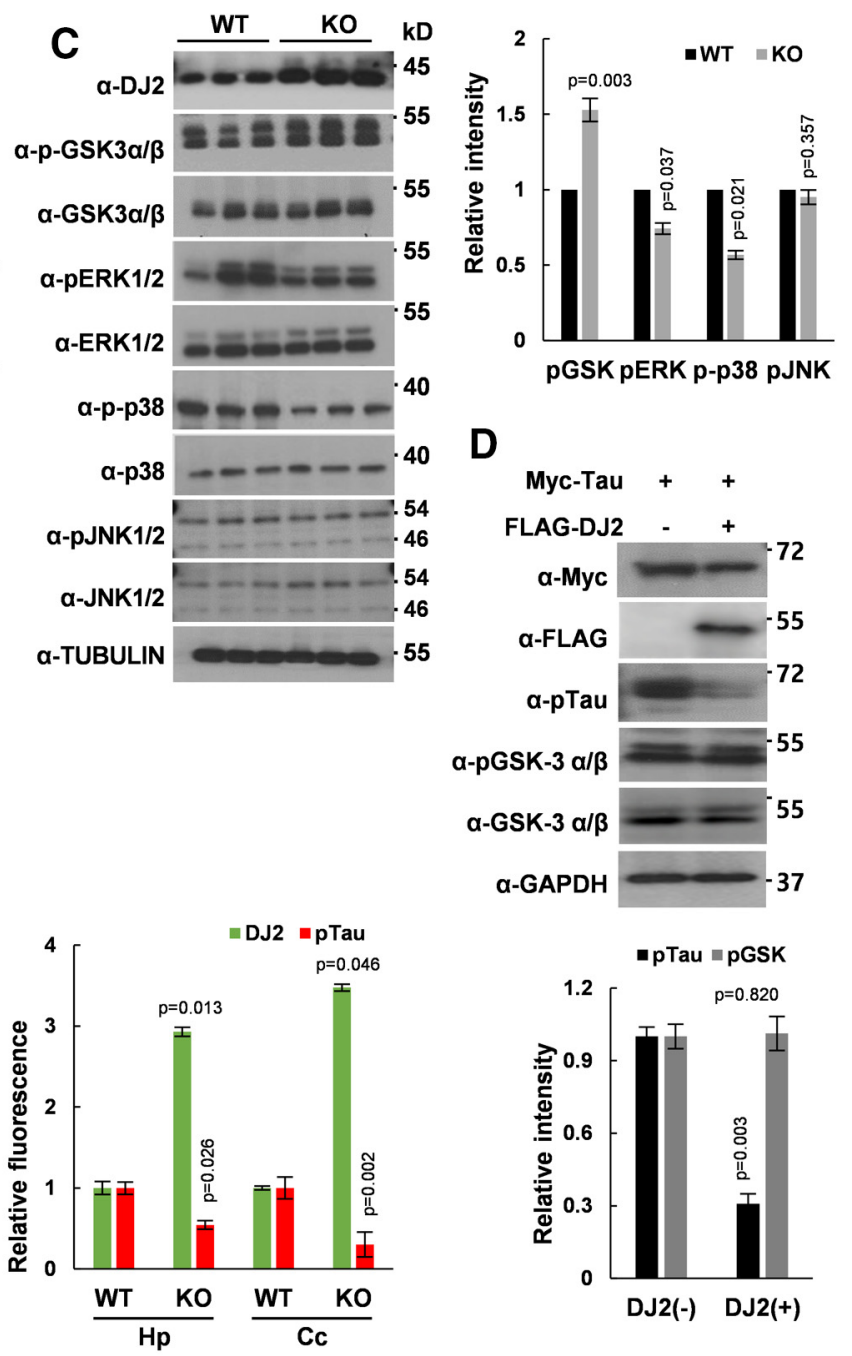

Figure 7. Knocking out Crbn attenuates pathologic phosphorylation of tau. $\boldsymbol{A}$, WBL of WT (Crbn $\left.{ }^{+/+}\right)$and KO (Crbn $\left.{ }^{-1-}\right)$ mice were subjected to immunoblot against the selected p-tau epitopes. Adjacent panels show statistics. Phospho/total ratio was calculated and represented as the mean \pm SD ( $n=3 ; 9$ mice/group). Student's $t$ test was used. $\boldsymbol{B}$, Brain tissues of WT $\left(\mathrm{Crbn}^{+/+}\right)$and $\mathrm{KO}\left(\mathrm{Crbn}^{-1-}\right)$ were cryosectioned and immunostained with AT8 (pTau) and DJ2 antibodies for $16 \mathrm{~h}$, incubated with Alexa Fluor-conjugated secondary antibodies for $1 \mathrm{~h}$, and imaged under confocal microscope equipped with $40 \times$ lens. Adjacent panels shows statistics, Student's $t$ test was used to calculate $p$ value for $n=6$. C, WBL of WT (Crbn ${ }^{+/+}$) and K0 $\left(\mathrm{Crbn}^{-1-}\right)$ mice were subjected to immunoblot against the selected tau-kinases. Adjacent panels show statistics. Phospho/total ratio was calculated and represented as the mean \pm SD ( $n=3$; 9 mice/group). Student's $t$ test was used. D, SH-SY5Y cells were transiently cotransfected with Myc-tau and FLAG-DJ2, and immunoblotted with the indicated antibodies. Student's $t$ test was used to calculate $p$ value for $n=3$.

blocked the interaction between CRBN and DJ2, as shown by coIP assay, while scrambled peptide could not (Fig. 10D,E). Peptides have played a remarkable role in the coherent design of small-molecule inhibitors and, in certain cases, have served as the drug themselves (Modell et al., 2016). Also, chemical knockdown of CRBN may not be a desirable strategy for the cells to sustain the recruitment and Ubn of endogenous substrates other than DJ2. Thus, peptides based on the hotspot residues can mask CRBN specifically, disrupt the interactions with DJ2 resulting in oppressed Ubn of DJ2, and may offer a promising approach for selective inhibition of pathologic tau phosphorylation.

\section{Discussion}

In this study, we sought to identify CRBN binding proteins and establish their physiological impact by exploring changes in the protein abundance after knocking out Crbn. Hsp70, DJ2, and tau were identified as endogenous substrates of CRBN, mediating their Ubn in a thalidomide-independent manner. We also found that the association of DJ2 with tau prevents its pathologic phosphorylation and consequent aggregation. Depletion of CRBN increases this chaperone activity of DJ2, resulting in decreased tau-tau interactions to form neurofibrillary tangles (NFTs) in vitro and in vivo. In accordance with these findings, the expression level of DJ2 was significantly higher in $\mathrm{Crbn}^{-1-}$ mice than in wild-type mice, thereby enabling the former to cope with environment- and aging-induced stress exposure (Fig. 11). We suggest that Ubn of DJ2 (and other substrates yet to be identified) by CRL4 ${ }^{\mathrm{CRBN}}$ may have a profound effect on the stress response to restore the basal homeostatic set point since chaperones are involved in diverse cellular activities serving the cell as a master concierge by constantly integrating signals from the surroundings with proteostasis (Hartl et al., 2011). Other E3 ligases have already been reported to ubiquitylate tau and Hsp70, including CHIP (C terminus of the Hsc70-interacting protein), axotrophin/ MARCH7, TRAF6 (TNF receptor-associated factor 6), and Parkin (Petrucelli et al., 2004; Babu et al., 2005; Moore et al., 2008; Flach et al., 2014; Soss et al., 2015). These pathways do not seem to be 

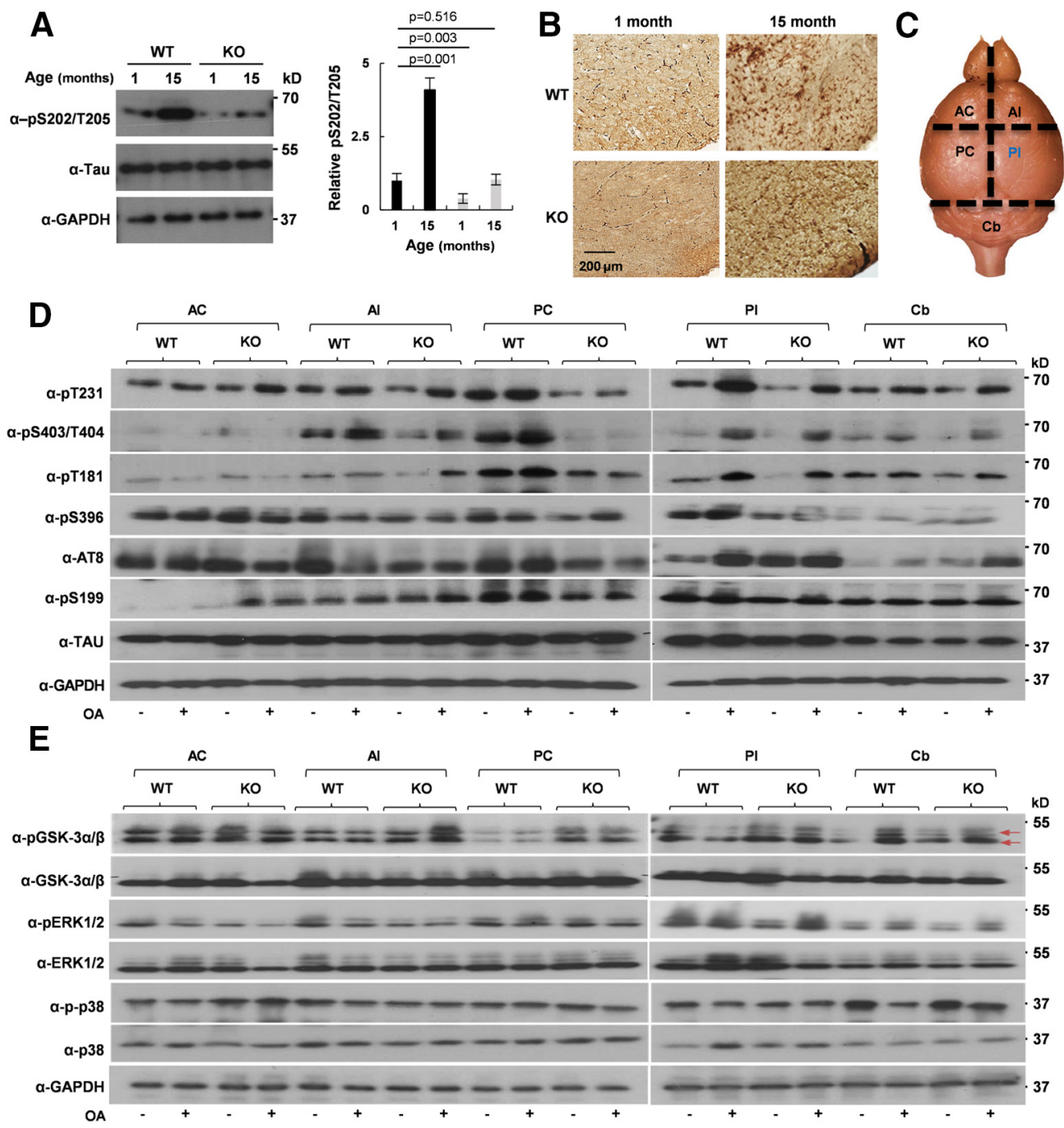

$\mathbf{F}$

(2)
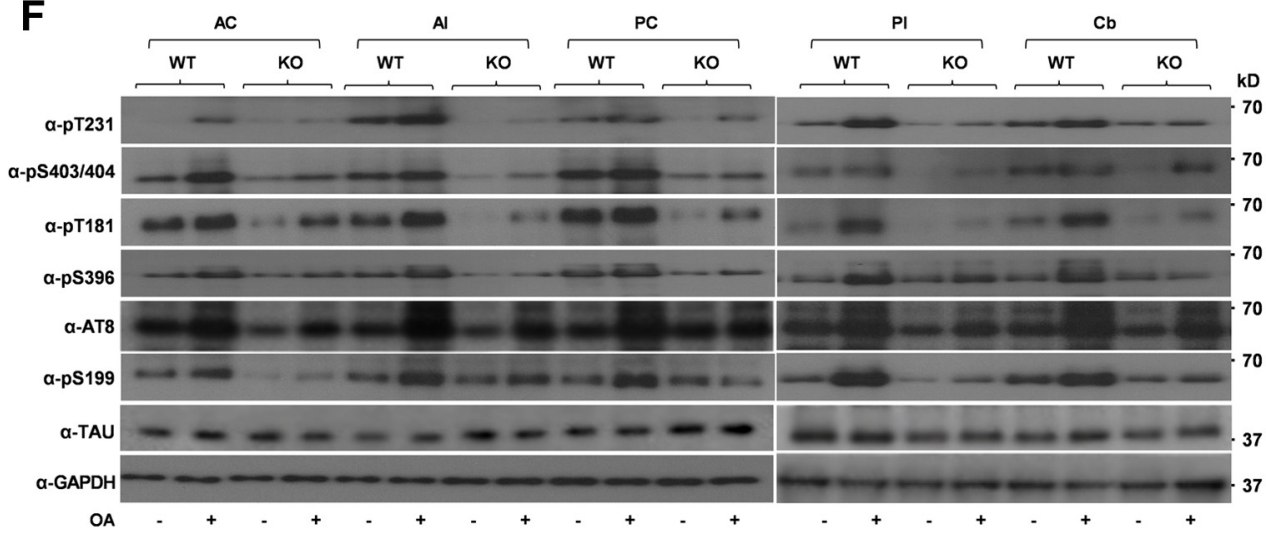

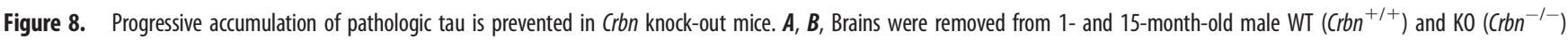
mice, and pTau level was measured using Western blot and DAB staining using AT8 antibody. Data represent the mean \pm SD $(n=5)$ using Student's $t$ test. C, Schematic representation of dissection. Mouse brains were dissected into certain anatomic parts, anterior contralateral (AC), anterior ipsilateral (Al), posterior contralateral (PC), posterior ipsilateral (PI), and cerebellum (Cb), for analysis with Western blotting. The PI region contains the lateral amygdala injection site. D, OA was stereotaxically injected into the brains of WT and KO mice. After $24 \mathrm{~h}$, dissected parts were lysed in RIPA buffer, and blotted with antibodies of the p-tau array as shown. $\boldsymbol{E}$, The same brain samples used in $\boldsymbol{D}$ were analyzed for three tau kinases (phospho and total forms), as shown in the panels. $F, O A$ was stereotaxically injected into the brains of WT and KO mice. After $7 \mathrm{~d}$, dissected parts were lysed in RIPA buffer and blotted with antibodies of the p-tau array, as shown.

affected in $\mathrm{Crbn}^{-1-}$ mice and cells, as reflected by Ubn assays, whereas DJ2 appears to be a specific substrate of CRBN.

DNAJA2, a closely related family member of DJ2, has been linked to tau homeostasis as an early protective factor for accretion of tau masses (Mok et al., 2018). Intriguingly, DNAJA2 was ranked as the second most accumulated chaperone in our LC-MS/MS analysis of WBLs of $\mathrm{Crbn}^{-1-}$ mice supporting the idea that these two members of the DNAJA family constitute a 
A
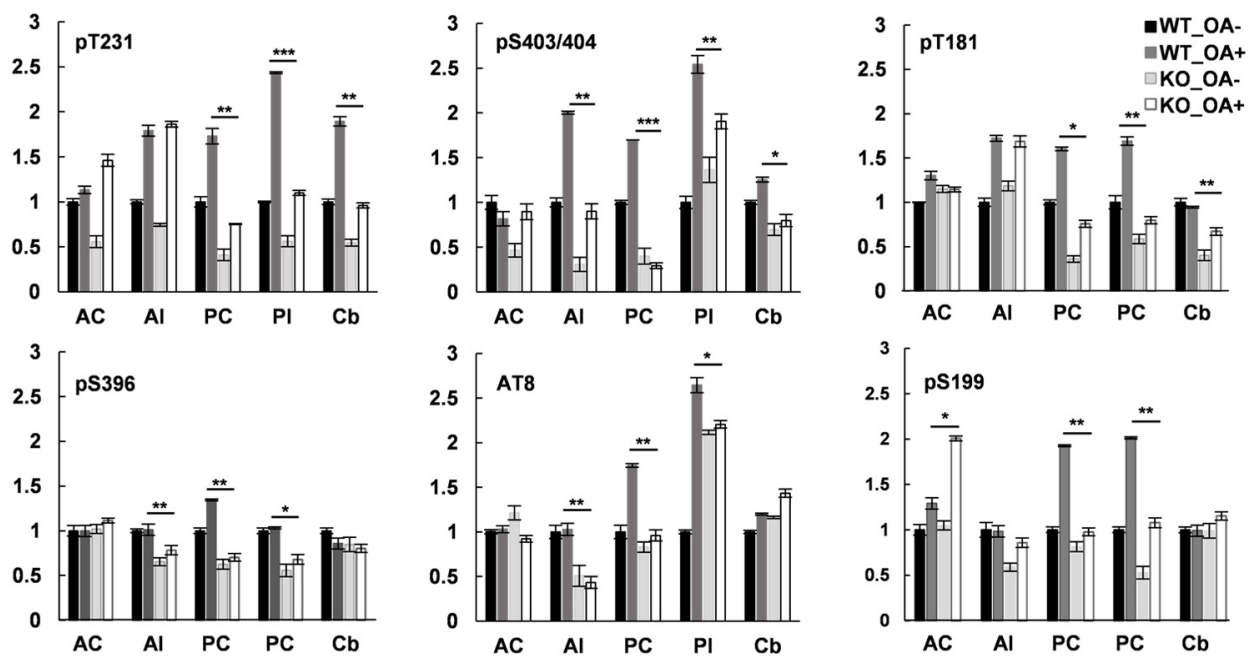

B
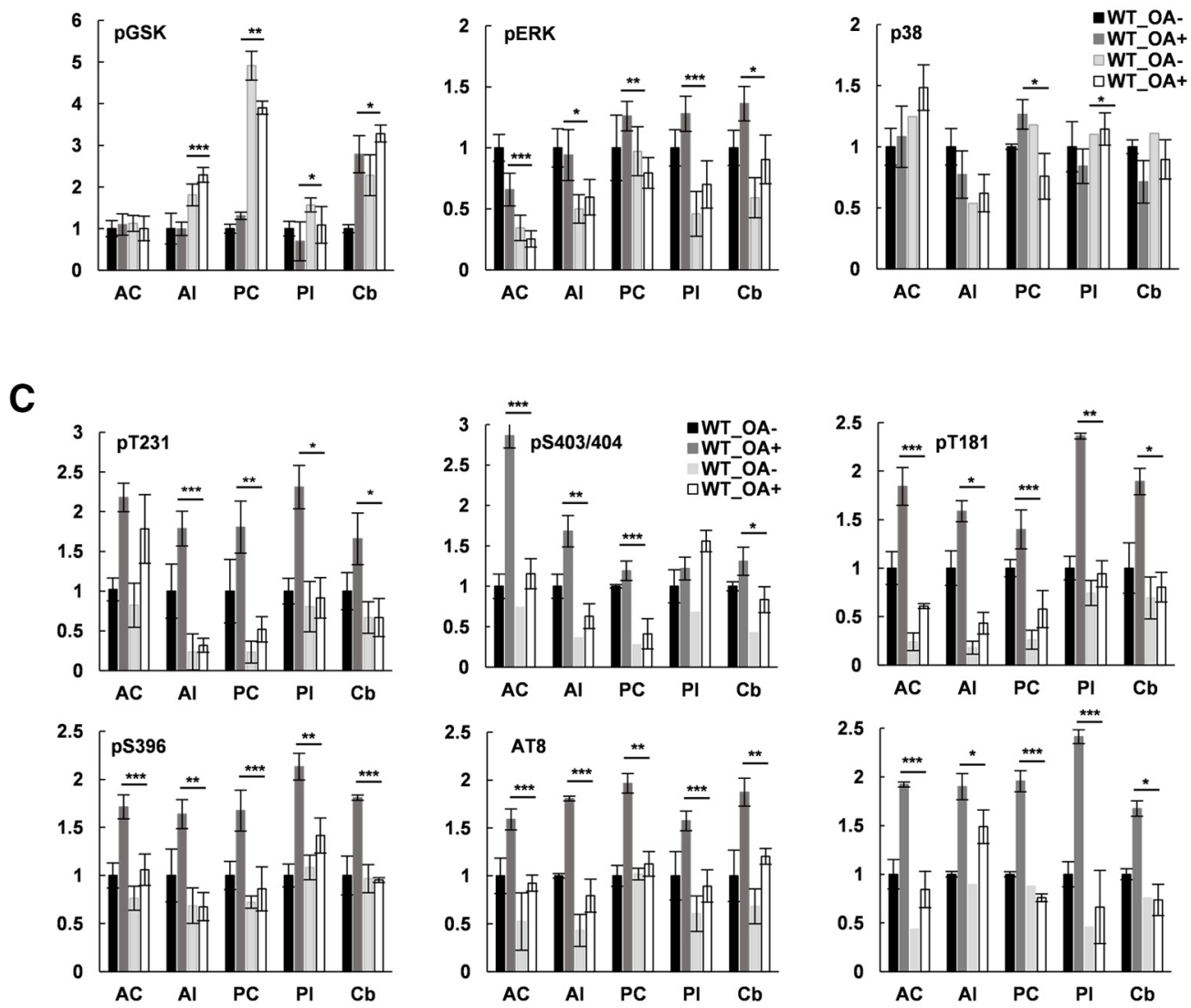

Figure 9. Progressive accumulation of pathologic tau is prevented in $C r b n$ knock-out mice. $A-C$, Densitometric analysis of panels $D-F$, respectively, in Figure 8 , with $n=6$ in each group of KO and WT mice is shown. Student's $t$ test was performed. Experiment was performed three times. ${ }^{*} p<0.05,{ }^{* *} p<0.01$, and ${ }^{* * *} p<0.001$.

piece of robust machinery in $\mathrm{Crbn}^{-1-}$ mice to modulate the aggregation of tau. As chaperones behave differently in certain conditions, these proteins can exhibit "anti-tau activity" in the presence of CRBN, while their "chaperone activity" is enhanced in the CRBN knock-out system. Thus, understanding of the chaperome regulation will be instrumental to the biology of neurodegeneration as the disease may proceed fast in their low expression.

The conformational plasticity of DJ2 to adapt to different substrate proteins can play a significant role in binding to different forms of tau to inhibit pathologic misfolding (Cuéllar et al., 2013). Thus, DJ2 may interpret the structural and chemical features of tau, and make decisions about its fate of trafficking, folding, or degrading. We have shown the robust impact of CRBN on the physiological role of DJ2 to modulate the accumulation of pathologic tau induced by various factors, such as stressors, OA, or heparin, presumably by leaving tau species as small-sized NFTs or even monomers. Hence CRBN-modulated activity of DJ2 to harvest monomeric and nonpathological tau may, therefore, contribute to the 
A
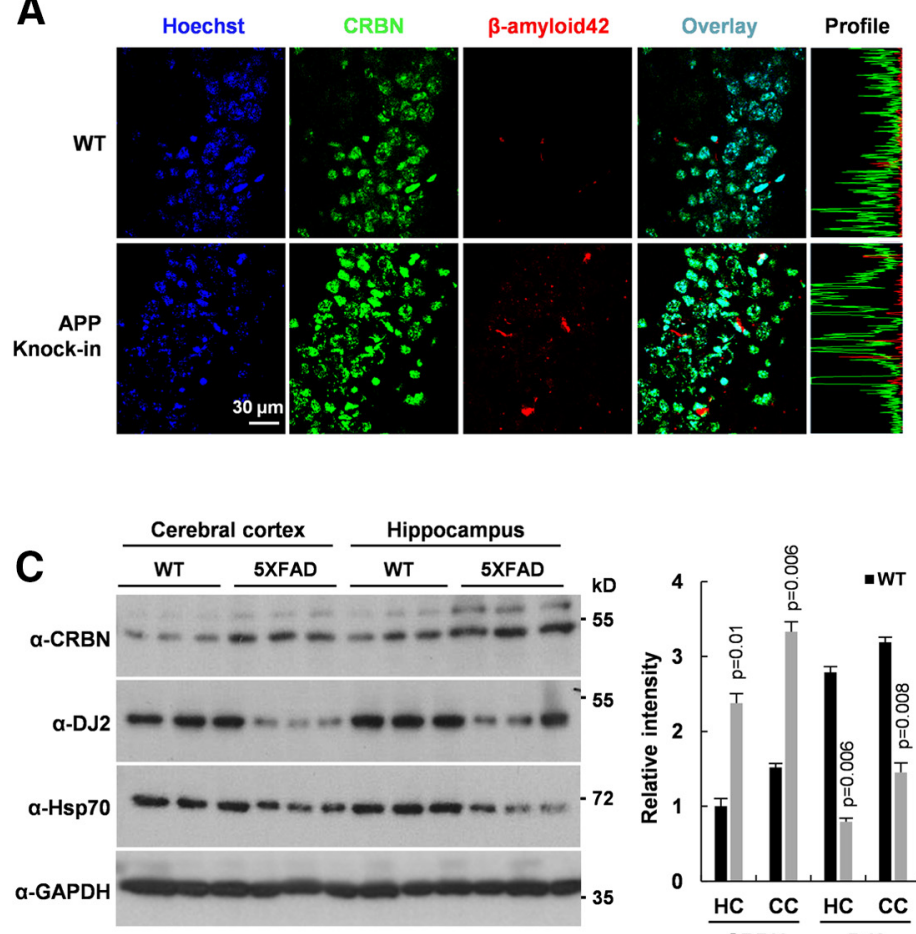

D

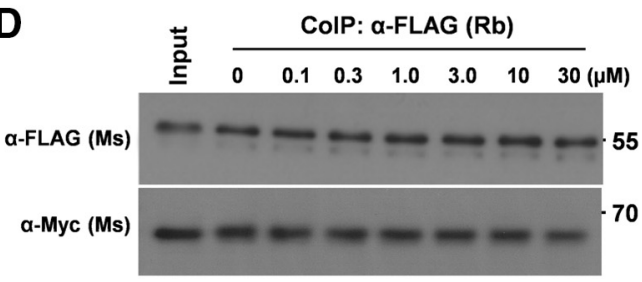

E

a-FLAG (Ms)

a-Myc (Ms)
B

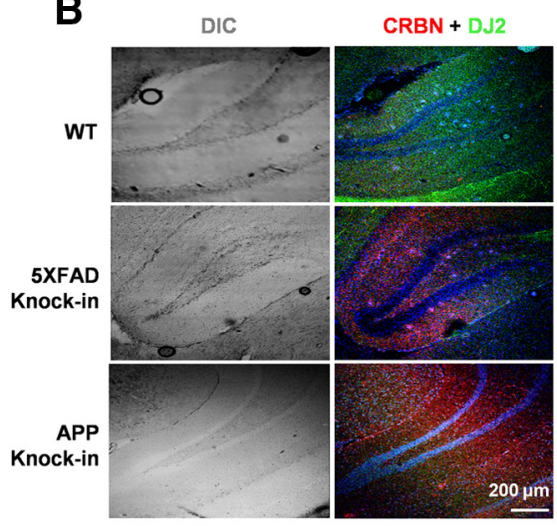

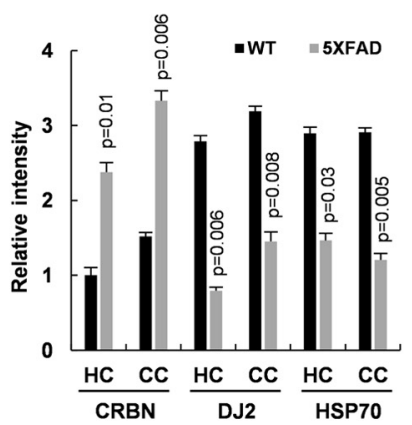
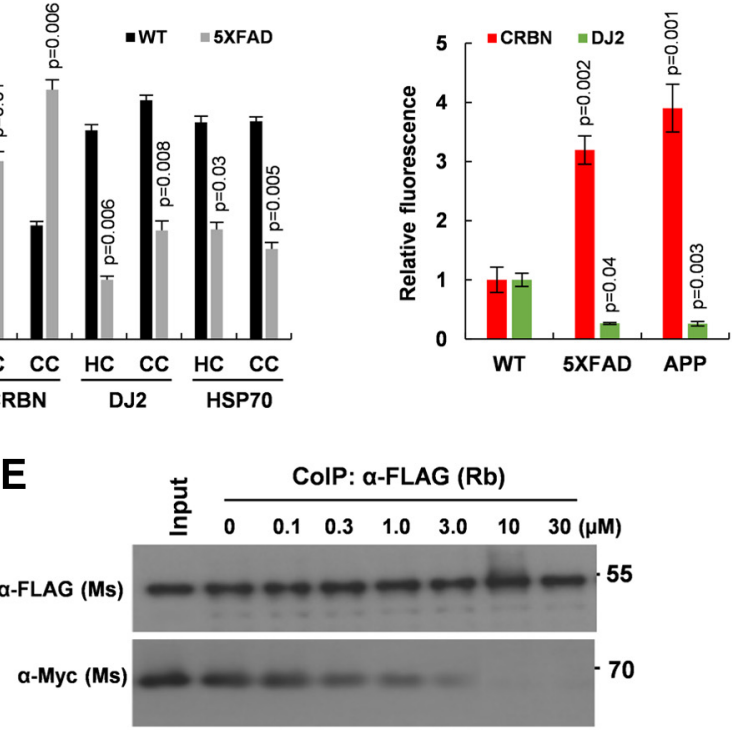

F

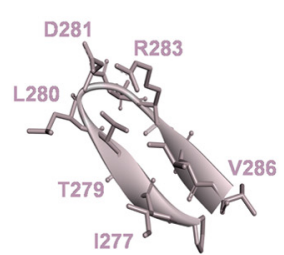

276-CPISTLDNRTIVC-286

DJ2 peptide

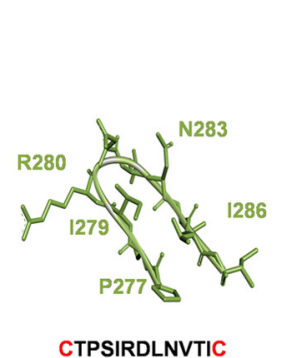

Scrambled peptide

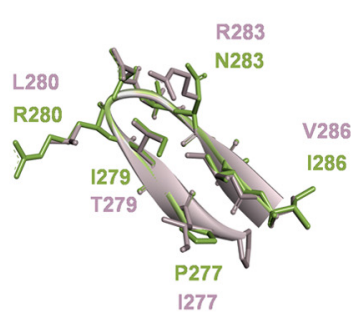

1277

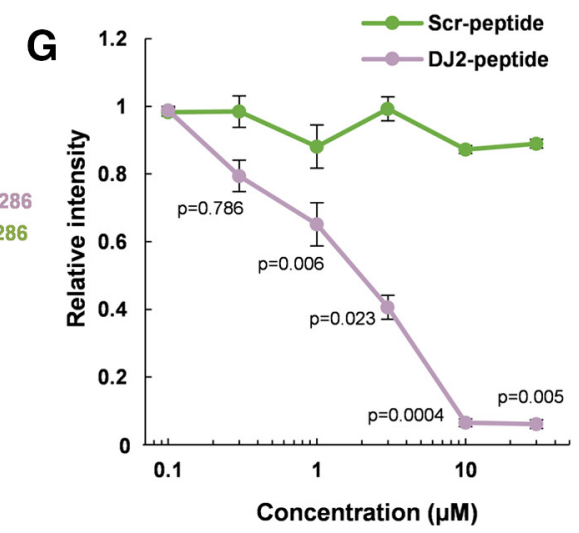

Figure 10. CRBN is a novel contributor for tauopathies. $A-C$, Brains were removed from 8-month-old male APP knock-in and 5XFAD mice; half of the brain was used for cryosectioning (A, $B$ ), and another half for Western blot analysis (C). Hippocampi were immunostained with APP, CRBN (Abnova), and DJ2 antibodies for $16 \mathrm{~h}$, and imaged under a confocal microscope equipped with $100 \times(\boldsymbol{A})$ and $10 \times(\boldsymbol{B})$ lenses. Images were quantified by ImageJ and represented as the mean \pm SD $(n=5)$. Student's $t$ test was used. $\boldsymbol{D}, \boldsymbol{E}$, SH-SY5Y cells were transiently cotransfected with Myc-DJ2 and FLAG-CRBN. Cellular extracts were treated with scrambled (D) or DJ2 peptide (E) for $24 \mathrm{~h}$. Cellular extracts were immunoprecipitated with $\alpha$-FLAG antibody from rabbit (Rb) and immunoblotted with Myc and FLAG antibodies from mouse (Ms) to get rid of the band of lgG heavy chain. $\boldsymbol{F}$, Sequence and 3D structure of scrambled peptide and DJ2 peptide inhibitor. Models were generated for a span of 51 aa of DJ2 (20 aa on both sides of the peptide) using Swiss model. $\mathbf{G}$, Statistical analysis of $\boldsymbol{D}$ and $\boldsymbol{E}$; data were represented as the mean \pm SD $(n=5)$. Student's $t$ test was used.

prevention of tauopathies. Additionally, DJ2 may recruit other client proteins as well to CRBN for their Ubn having respective physiological effects. To our knowledge, this is the first report to identify the chaperone activity of DJ2 for tau, as previously only the anti-tau activity of DJ2 involving the Ubn of tau was reported.
At present, two studies have evaluated the gene expression profiles of CRBN and DJ2 in human Alzheimer's disease brain samples, our results are consistent with both of them (Brehme et al., 2014; Kuzma et al., 2016). These studies showed that 32\% of chaperones including DJ2 are repressed during aging and $\mathrm{AD}$, whereas NIAGADS (National Institute on Aging Genetics of 


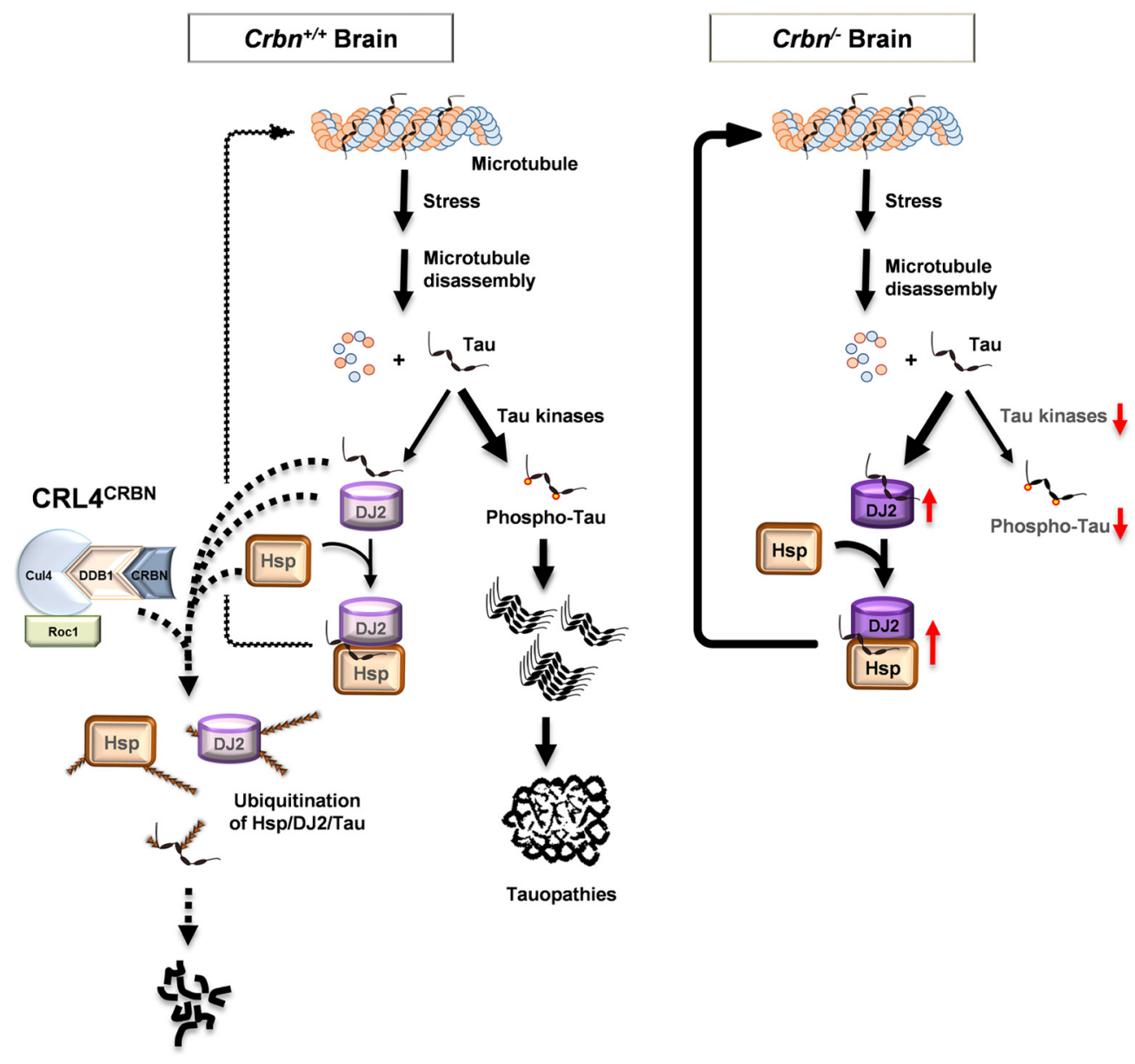

Figure 11. Proposed model for the role of CRBN in tau pathology by regulating the availability of chaperones. Atypical disengagement of tau from the microtubules results in a concomitant increase in the cytosolic fraction of p-tau, which is likely to be the key event leading to tauopathies. DJ2-mediated refolding/clearance of cytosolic p-tau may constrain its aggregation and stimulate reassociation with microtubules. CRBN mitigates the DJ2-mediated inhibition of pathologic tau species.

Alzheimer's Disease Data Storage Site) reported an elevated expression of $\mathrm{CRBN}$ in the genetic architecture of $\mathrm{AD}$. In addition, an elevation of CRBN in 5XFAD and $\mathrm{APP}^{\mathrm{NL}-\mathrm{G}-\mathrm{F}}$ knock-in mice also classifies CRBN as a relevant factor for Alzheimer's disease and other neuropathies. This predicts two roles of CRBN in these mice. First, the induction of high CRBN as an early molecular pathologic feature contributes to the onset of Alzheimer's disease in 5XFAD and APP ${ }^{\text {NL-G-F }}$ knock-in mice in a later stage of neuropathy. Second, CRBN may degrade other specific chaperones, resulting in the formation of APP plaques.

In our previous study, we reported the resilient behavior of the $\mathrm{Crbn}^{-1-}$ cell line on exposure to various cell death-promoting stimuli (Lee et al., 2015). LC-MS/MS analysis of WBLs $\left(\mathrm{Crbn}^{-/-}\right.$vs $\left.\mathrm{Crbn}{ }^{+/+}\right)$shows a significant increase in the levels of chaperones, cochaperones, and various antioxidant proteins, including thioredoxin reductase 1 and 2, Cryz Quinone oxidoreductase, and cytochrome $\mathrm{P} 450$ reductase. Interestingly, few other important proteins were also abundant in $\mathrm{Crbn}^{-1-}$ mice. For instance, glutathione $S$-transferase $\mathrm{P} 1$ and $\mathrm{Mu} 7$ have a role in glutathione metabolic processes, Prohibitin-2 protein with pleiotropic attributes, and 11 phosphatases (Extended Data Table 31). These candidates might be direct or downstream targets of CRBN, rendering it an important recruiter of crucial substrates. Together with the current findings, attainment of resistance against stressors is explainable, when CRBN is knocked out.

Because the processes of misfolding and aggregation are the primary origins of neuropathology, they are now recognized as common molecular events for a large number of human diseases, including Alzheimer's disease, Huntington's disease, Kennedy's disease, spinocerebellar ataxias, Parkinson's disease, and amyotrophic lateral sclerosis. Hence, balanced degradation of chaperones is central to the cell to allow it to acquire the excess capacity needed to buffer against protein misfolding. Based on the protein expression profile of WBLs, we expect that other chaperones, such as DNAJB1 and DNAJB6, might possess enhanced activity for their target proteins in $\mathrm{Crbn}^{-1-}$ mice (Table 3). Overall, it is essential to note that many of the foremost mediators of the stress response and chronic ultra-mild stress, such as chaperones, cochaperones, AMPK, and antioxidant systems, contribute to these processes through several reinforcing positive feedback loops (Kriete et al., 2010). This may be the basis for the markedly overstated and persistent elevation of the stress responses seen in $\mathrm{Crbn}^{-1-}$ cell lines and mice. Because aberrant phosphorylation of tau is a hallmark of neurodegenerative disorders, decreased activity of certain tau kinases in $\mathrm{Crbn}^{-1-}$ mice may contribute to alterations in tau phosphorylation in the context of tauopathies. Interestingly, the JNK pathway was not affected in $\mathrm{Crbn}^{-1-}$ mice, as we observed in our previous study (Kang et al., 2016).

Following our previous investigation of the role of AMPK, we have elaborated in the present study the role of CRBN in governing the activity of chaperones. This detailed study of stressresponse mechanisms will provide new insights into the potential of an organism to counteract protein aggregation and enable the development of new therapeutic strategies against 
neurodegenerative diseases. CRBN and DJ2 could be the novel therapeutic targets to halt the propagation of tau pathology by restoring neuronal proteostasis. Recently, a chemical-induced CRBN knockout was introduced using Homo-PROTACs (IMiD-based proteolysis-targeting chimeras). It can efficiently recruit CRBN, leading to its Ubn and proteasomal degradation (Steinebach et al., 2018). Strategies like peptide inhibitor and chemical knockdown may lead to a useful therapeutic invention against neurodegeneration. Armed with the appropriate target proteins and mechanisms, we will be able to peer much deeper into the Alzheimer's disease brain and disclose its ambiguities.

\section{References}

Abisambra JF, Jinwal UK, Suntharalingam A, Arulselvam K, Brady S, Cockman M, Jin Y, Zhang B, Dickey CA (2012) DnaJA1 antagonizes constitutive Hsp70-mediated stabilization of tau. J Mol Biol 421:653-661.

Babu JR, Geetha T, Wooten MW (2005) Sequestosome 1/p62 shuttles polyubiquitinated tau for proteasomal degradation. J Neurochem 94:192-203.

Baker S, Götz J (2016) A local insult of okadaic acid in wild-type mice induces tau phosphorylation and protein aggregation in anatomically distinct brain regions. Acta Neuropathol Commun 4:32.

Balchin D, Hayer-Hartl M, Hartl FU (2016) In vivo aspects of protein folding and quality control. Science 353:aac4354.

Bavley CC, Rice RC, Fischer DK, Fakira AK, Byrne M, Kosovsky M, Rizzo BK, Del Prete D, Alaedini A, Morón JA, Higgins JJ, D’Adamio L, Rajadhyaksha AM (2018) Rescue of learning and memory deficits in the human nonsyndromic intellectual disability cereblon knock-out mouse model by targeting the AMP-activated protein kinase-mTORC1 translational pathway. J Neurosci 38:2780-2795.

Brehme M, Voisine C, Rolland T, Wachi S, Soper JH, Zhu Y, Orton K, Villella A, Garza D, Vidal M, Ge H, Morimoto RI (2014) A chaperome subnetwork safeguards proteostasis in aging and neurodegenerative disease. Cell Rep 9:1135-1150.

Chen Y-A, Peng Y-J, Hu M-C, Huang J-J, Chien Y-C, Wu J-T, Chen T-Y, Tang C-Y (2015) The cullin 4A/B-DDB1-cereblon E3 ubiquitin ligase complex mediates the degradation of CLC-1 chloride channels. Sci Rep 5:10667.

Choi TY, Lee SH, Kim YJ, Bae JR, Lee KM, Jo Y, Kim SJ, Lee AR, Choi S, Choi LM, Bang S, Song MR, Chung J, Lee KJ, Kim SH, Park CS, Choi SY (2018) Cereblon maintains synaptic and cognitive function by regulating BK channel. J Neurosci 38:3571-3583.

Cuéllar J, Perales-Calvo J, Muga A, Valpuesta JM, Moro F (2013) Structural insights into the chaperone activity of the $40-\mathrm{kDa}$ heat shock protein DnaJ: binding and remodeling of a native substrate. J Biol Chem 288:15065-15074.

De Los Rios P, Goloubinoff P (2016) Hsp70 chaperones use ATP to remodel native protein oligomers and stable aggregates by entropic pulling. Nat Struct Mol Biol 23:766-769.

Del Prete D, Rice RC, Rajadhyaksha AM, D'Adamio L (2016) Amyloid precursor protein (APP) may act as a substrate and a recognition unit for CRL4CRBN and Stub1 E3 ligases facilitating ubiquitination of proteins involved in presynaptic functions and neurodegeneration. J Biol Chem 291:17209-17227.

Flach K, Ramminger E, Hilbrich I, Arsalan-Werner A, Albrecht F, Herrmann L, Goedert M, Arendt T, Holzer M (2014) Axotrophin/MARCH7 acts as an E3 ubiquitin ligase and ubiquitinates tau protein in vitro impairing microtubule binding. Biochim Biophys Acta 1842:1527-1538.

Goedert M, Masuda-Suzukake M, Falcon B (2017) Like prions: the propagation of aggregated tau and $\alpha$-synuclein in neurodegeneration. Brain 140:266-278.

Gong CX, Lidsky T, Wegiel J, Zuck L, Grundke-Iqbal I, Iqbal K (2000) Phosphorylation of microtubule-associated protein tau is regulated by protein phosphatase 2A in mammalian brain. Implications for neurofibrillary degeneration in Alzheimer's disease. J Biol Chem 275:5535-5544.

Hartl FU, Bracher A, Hayer-Hartl M (2011) Molecular chaperones in protein folding and proteostasis. Nature 475:324-332.

Hornbeck PV, Kornhauser JM, Tkachev S, Zhang B, Skrzypek E, Murray B, Latham V, Sullivan M (2012) PhosphoSitePlus: a comprehensive resource for investigating the structure and function of experimentally determined post-translational modifications in man and mouse. Nucleic Acids Res 40:D261-D270.

Hoshino T, Murao N, Namba T, Takehara M, Adachi H, Katsuno M, Sobue G, Matsushima T, Suzuki T, Mizushima T (2011) Suppression of Alzheimer's disease-related phenotypes by expression of heat shock protein 70 in mice. J Neurosci 31:5225-5234.

Joseph J, Cole G, Head E, Ingram D (2009) Nutrition, brain aging, and neurodegeneration. J Neurosci 29:12795-12801.

Kang J-A, Park S-H, Jeong SP, Han M-H, Lee C-R, Lee KM, Kim N, Song MR, Choi M, Ye M, Jung G, Lee W-W, Eom SH, Park C-S, Park S-G (2016) Epigenetic regulation of Kcna3-encoding Kv1.3 potassium channel by cereblon contributes to regulation of $\mathrm{CD} 4{ }^{+}$T-cell activation. Proc Natl Acad Sci U S A 113:8771-8776.

Kozakov D, Hall DR, Xia B, Porter KA, Padhorny D, Yueh C, Beglov D, Vajda S (2017) The ClusPro web server for protein-protein docking. Nat Protoc 12:255-278.

Kriete A, Bosl WJ, Booker G (2010) Rule-based cell systems model of aging using feedback loop motifs mediated by stress responses. PLoS Comput Biol 6:e1000820.

Kuzma A, Valladares O, Cweibel R, Greenfest-Allen E, Childress DM, Malamon J, Gangadharan P, Zhao Y, Qu L, Leung YY, Naj AC, Stoeckert CJ, Schellenberg GD, Wang L-S (2016) NIAGADS: the NIA genetics of Alzheimer's disease data storage site. Alzheimers Dement 12:1200-1203.

Lee KM, Jo S, Kim H, Lee J, Park CS (2011) Functional modulation of AMPactivated protein kinase by cereblon. Biochim Biophys Acta 1813:448455.

Lee KM, Yang S-J, Kim YD, Choi YD, Nam JH, Choi CS, Choi H-S, Park C-S (2013) Disruption of the cereblon gene enhances hepatic AMPK activity and prevents high-fat diet-induced obesity and insulin resistance in mice. Diabetes 62:1855-1864.

Lee KM, Yang SJ, Park S, Choi YD, Shin HK, Pak JH, Park CS, Kim I (2015) Depletion of the cereblon gene activates the unfolded protein response and protects cells from ER stress-induced cell death. Biochem Biophys Res Commun 458:34-39.

Lim S, Haque MM, Kim D, Kim DJ, Kim YK (2014) Cell-based models to investigate Tau aggregation. Comput Struct Biotechnol J 12:7-13.

Lindberg I, Shorter J, Wiseman RL, Chiti F, Dickey CA, McLean PJ (2015) Chaperones in neurodegeneration. J Neurosci 35:13853-13859.

Liu L, Drouet V, Wu JW, Witter MP, Small SA, Clelland C, Duff K (2012) Trans-synaptic spread of tau pathology in vivo. PLoS One 7:e31302.

Liu Y, Huang X, He X, Zhou Y, Jiang X, Chen-Kiang S, Jaffrey SR, Xu G (2015) A novel effect of thalidomide and its analogs: suppression of cereblon ubiquitination enhances ubiquitin ligase function. FASEB J 29:4829-4839.

Modell AE, Blosser SL, Arora PS (2016) Systematic targeting of protein-protein interactions. Trends Pharmacol Sci 37:702-713.

Mogk A, Bukau B, Kampinga HH (2018) Cellular handling of protein aggregates by disaggregation machines. Mol Cell 69:214-226.

Mok S, Condello C, Freilich R, Gillies A, Arhar T, Oroz J, Kadavath H, Julien O, Assimon VA, Rauch JN, Dunyak BM, Lee J, Tsai FTF, Wilson MR, Zweckstetter M, Dickey CA, Gestwicki JE (2018) Mapping interactions with the chaperone network reveals factors that protect against tau aggregation. Nat Struct Mol Biol 25:384-393.

Moore DJ, West AB, Dikeman DA, Dawson VL, Dawson TM (2008) Parkin mediates the degradation-independent ubiquitination of Hsp70. J Neurochem 105:1806-1819.

Nguyen T, Van Lee JE, Sweredoski MJ, Yang SJ, Jeon SJ, Harrison JS, Yim JH, Lee SG, Handa H, Kuhlman B, Jeong JS, Reitsma JM, Park CS, Hess S, Deshaies RJ (2016) Glutamine triggers acetylation-dependent degradation of glutamine synthetase via the thalidomide receptor cereblon. Mol Cell 61:809-820.

Nillegoda NB, Kirstein J, Szlachcic A, Berynskyy M, Stank A, Stengel F, Arnsburg K, Gao X, Scior A, Aebersold R, Guilbride DL, Wade RC, Morimoto RI, Mayer MP, Bukau B (2015) Crucial HSP70 co-chaperone complex unlocks metazoan protein disaggregation. Nature 524:247-251.

Petrucelli L, Dickson D, Kehoe K, Taylor J, Snyder H, Grover A, De Lucia M, McGowan E, Lewis J, Prihar G, Kim J, Dillmann WH, Browne SE, Hall A, Voellmy R, Tsuboi Y, Dawson TM, Wolozin B, Hardy J, Hutton M (2004) CHIP and Hsp70 regulate tau ubiquitination, degradation and aggregation. Hum Mol Genet 13:703-714. 
Qiu X-B, Shao Y-M, Miao S, Wang L (2006) The diversity of the DnaJ/Hsp40 family, the crucial partners for Hsp70 chaperones. Cell Mol Life Sci 63:2560-2570.

Shimojo M, Takuwa H, Takado Y, Tokunaga M, Tsukamoto S, Minatohara K, Ono M, Seki C, Maeda J, Urushihata T, Minamihisamatsu T, Aoki I, Kawamura K, Zhang MR, Suhara T, Sahara N, Higuchi M (2020) Selective disruption of inhibitory synapses leading to neuronal hyperexcitability at an early stage of tau pathogenesis in a mouse model. J Neurosci 40:3491-3501.

Sievers QL, Petzold G, Bunker RD, Renneville A, Słabicki M, Liddicoat BJ, Abdulrahman W, Mikkelsen T, Ebert BL, Thomä NH (2018) Defining the human $\mathrm{C} 2 \mathrm{H} 2$ zinc finger degrome targeted by thalidomide analogs through CRBN. Science 362:eaat0572.

Song T, Liang S, Liu J, Zhang T, Yin Y, Geng C, Gao S, Feng Y, Xu H, Guo D, Roberts A, Gu Y, Cang Y (2018) CRL4 antagonizes SCFFbxo7-mediated turnover of cereblon and BK channel to regulate learning and memory. PLOS Genet 14:e1007165.

Soss SE, Rose KL, Hill S, Jouan S, Chazin WJ (2015) Biochemical and proteomic analysis of ubiquitination of $\mathrm{Hsc} 70$ and $\mathrm{Hsp} 70$ by the E3 ligase CHIP. PLoS One 10:e128240.
Steinebach C, Lindner S, Udeshi ND, Mani DC, Kehm H, Köpff S, Carr SA, Gütschow M, Krönke J (2018) Homo-PROTACs for the chemical knockdown of cereblon. ACS Chem Biol 13:2771-2782.

Vergara C, Houben S, Suain V, Yilmaz Z, De Decker R, Vanden Dries V, Boom A, Mansour S, Leroy K, Ando K, Brion J-P (2019) Amyloid- $\beta$ pathology enhances pathological fibrillary tau seeding induced by Alzheimer PHF in vivo. Acta Neuropathol 137:397-412.

Yang J, Yan R, Roy A, Xu D, Poisson J, Zhang Y (2015) The I-TASSER Suite: protein structure and function prediction. Nat Methods 12:7-8.

Yang SJ, Jeon SJ, Van Nguyen T, Deshaies RJ, Park CS, Lee KM (2020) Ubiquitin-dependent proteasomal degradation of AMPK gamma subunit by cereblon inhibits AMPK activity. Biochim Biophys Acta Mol Cell Res 1867:118729.

Yates JR, Link AJ, Eng J, Schieltz DM, Carmack E, Mize GJ, Morris DR, Garvik BM III (1999) Direct analysis of protein complexes using mass spectrometry. Nat Biotechnol 17:676-682.

Zhu YX, Braggio E, Shi CX, Kortuem KM, Bruins LA, Schmidt JE, Chang XB, Langlais P, Luo M, Jedlowski P, LaPlant B, Laumann K, Fonseca R, Bergsagel PL, Mikhael J, Lacy M, Champion MD, Stewart AK (2014) Identification of cereblon-binding proteins and relationship with response and survival after IMiDs in multiple myeloma. Blood 124:536-545. 